\title{
A COMPREHENSIVE SCENARIO INTERVENTION TYPOLOGY
}

\author{
Megan M. Crawford1
}

\begin{abstract}
:
Scenario planning, as a recognised organisational intervention, has steadily grown in popularity since the mid20 th century. To date, there are arguably as many methods and techniques as there are practitioners, with applications across nearly all sectors of public and private industry. Many feel that scenario planning is forever consigned to the realm of chaos, incapable of being clearly defined. We disagree and see the field as a collective of experiences and knowledge that play upon a theme, where emerging realities slowly reveal a structure to the system. In response, we propose a comprehensive typology for scenario planning interventions - the Comprehensive Scenario Intervention typology - which incorporates all dimensions of existing typologies along with additional dimensions and functions that reflect previously unrecognized and emergent topics relevant to understanding the critical realities of an intervention. The Comprehensive Scenario Intervention typology expands the scope of scenario planning interventions and adds to the theoretical foundation of the field.
\end{abstract}

Keywords: scenario planning, typology, intervention, profile

Abbreviations: SP, scenario planning; CSI, Comprehensive Scenario Intervention; BHDEF typology, Börjeson, Höjer, Drebord, Ekvall, \& Finnveden, 2006; DL typology, Ducot \& Lubben, 1980; HV typology, Heugens \& van Oosterhout, 2001; PV typology, Pulver \& VanDeveer, 2007; VAV typology, van de Riet, Aazami, \& van Rhee, 2008; VRVR typology, van Notten, Rotmans, van Asselt, \& Rothman, 2003; WE typology, Wilkinson \& Eidinow, 2008; WKM typology, Wilkinson, Kupers, \& Mangalagiu, 2013; CIA, Cross-impact analysis; TIA, Trend-impact analysis; IL, Intuitive Logics; MSG, Massive Scenario Generation; IPCC, Intergovernmental Panel on Climate Change; DOI, Department of Interior; FEMA, The Federal Emergency Management Agency; VERA, VERA-Forward Visions on the European Research Area; RTDI, research, technology, development and innovation; RIMA, reflexive interventionist or multi-agent based; ESPAS, European Strategy and Policy Analysis System

\section{Introduction}

Scenario planning (SP), as a recognised organisational intervention, has been in practice in the west since the post-war period, largely due to the pioneering efforts of Herman Kahn at the RAND Corporation (1948-1961), and later Pierre Wack at Royal Dutch Shell (1971-1982). The methods continue to develop along pragmatic lines, with an almost 'trial by fire' effort. With SP appreciating the better part of a century in use, we should take this time to assess what has emerged - from both academic inquiry and field applications - and determine where we can go from here. The field is rich with typologies, schools, theoretical development, and an almost anatomical map of scenario characteristics. However, as true today as in decades past, are the numerous and ever-emerging methods and schools of SP. These differences are as responsible for expanding the field of SP as they are for introducing obstacles to that same field. Some feel that SP is forever consigned to the realm of chaos, incapable of being clearly defined in any manner. We disagree with this view, and see the field of SP as a collective of experiences and knowledge that play upon a theme, where realities have been revealed in absence of pre-defined boundaries. To answer this problem, we offer a tool that is both clear in definition and flexible in application, therefore introducing a guidance system for the broadest range of SP interventions. The "Comprehensive Scenario Intervention" (CSI) typology complements the collective efforts of the field and brings greater robustness and validity to the practice, while allowing for expanded applications beyond scenario science into the broader field of futures studies.

Huss and Honton (1987) identify three major schools of SP: Intuitive Logics (IL: Ogilvy and Mandel, 1984), Cross-Impact Analysis (CIA: Gordon, 1994a), and Trend-Impact Analysis (TIA: Gordon, 1994b). Sometimes the IL approach is referred to as the 'Shell approach' due to its early popularity with Pierre Wack when employed at Royal Dutch Shell (Wack, 1985a; Wack, 1985b) or the 'SRI school' due to the pioneering days at the Stanford Research Institute (International, 2019). Bradfield, et al. (2005) add to this list the French School of La Prospective, developed by Gaston Berger, and expanded by Godet (1987), and combine CIA and TIA under the single umbrella of Probabilistic Modified Trends. Bradfield, et al., along with Amer, et al. (2013) offer

1 Corresponding author: University of Strathclyde, 199 Cathedral St., Glasgow G11XQ, UK megan.m.crawford@strath.ac.uk 
comprehensive reviews of the four SP schools, and describe the three main scenario approaches as plausibility based (IL), preference based (La Prospective) and probability based (Probabilistic Modified Trends). Chermack (2011) identifies 10 schools of SP, though several are modifications of the main three.

The schools of SP give way to the collection of potential scenario dimensions. Any typology of SP must have a working definition of what a "scenario" could or should be. Much like the pursuit of a unifying theory, there is a plethora of definitions (for reviews see Amer et al., 2013; Börjeson, Höjer et al., 2006; Bradfield, Wright et al., 2005; Chermack, 2018; Mackay and McKiernan, 2018; Stewart, 2008). Recently, however, Spaniol and Rowland (2018a) take the field to task, and develop an operant, working definition of what scenarios are, based on the overarching elements of existing definitions from within futures and foresight sciences. From their analyses, the main (possibly necessary) components of scenarios are that they "have a temporal property rooted in the future and reference external forces in that context; scenarios should be possible and plausible while taking the proper form of a story or narrative description; and that scenarios exist in sets that are systematically prepared to coexist as meaningful alternatives to one another" (p. 1). As Dator $(2009$, p. 6) puts simply, scenario practitioners study "images of the future".

Another major issue in the SP literature is the multi-faceted approach to theoretical and methodological development. A regular argument encountered is that SP suffers from a dismal theoretical grounding (see Bradfield R. M., 2008; Chermack, 2002; Martelli, 2001; Spaniol and Rowland, 2018b). However, we believe this perspective deserves a reinterpretation, where the field has produced a richness in theory (and method), where many discuss potential components that could contribute to a foundational theory. Inayatullah (2008) offers a strong approach for framing perspectives. By integrating a variety of futures and foresight studies and building on their concepts, Inayatullah identifies six foundational concepts, six questions to address, and six pillars of futures studies. Futures thinking is conceptually divided into the used future (using someone else's desires), the disowned future (ignoring other paths), alternative futures (range of futures), alignment (holistic connections), models of social change (levels of control), and use of the future (functionality). The six questions to ask to aid in creating the conceptual future space are: 1) What is your prediction? 2) Which future are you afraid of? 3) What are your future's hidden assumptions? 4) What are the alternatives to your future? 5) What is your preferred future? 6) How might you get there? Inayatullah's six pillars of futures studies are mapping (past, present and future), anticipation (forward-casting), timing the future (metaphors), deepening the future (details), creating alternatives (broaden), transforming the future (preferences). Amer et al. (2013) develop insightful questions, focusing heavily on the methods, that offer practical application to any scenario work. Bishop et al. (2007) help standardise the system of language in the practice in their catalog of scenario techniques. Millet (2003) lists three major challenges to the efficacy and utility of SP as a method of intervention: resolve scenario definitions and methods, clarify and expand scenario applications, and make the practice less resource heavy. The CSI typology aims to address Millet's second challenge - clarify and expand scenario applications - and by extension bring clarity and affordability to his other challenges. Balarezo and Nielson (2017) present a better fitting methodological outline for exploring the SP intervention framework by dividing the intervention across antecedents, processes, outcomes and variables. This sets the perspective of SP as an intervention apart from SP techniques. Chermack (2011) manages to take these fragments of the field and integrate them into arguably the most comprehensive theoretical foundation for SP, to date. Chermack's Scenario Planning Theory is comprised of six domains: dialogue, learning, mental models, decision making, leadership, and organisation performance/change theories. His reasoning is that more than any other domains, these six have the highest repetitious mention and use within the SP literature. Chermack's proposed theory is still quite recent, and understandably requires a fair bit of empirical work for support. To this end, we hope to show how the CSI typology and the integrated conceptual theories of the field mutually support one another, thus strengthening our collective attempts to define a robust and valid foundation for the field of SP.

The aims of a SP intervention are to challenge practitioners' (i.e. the individuals participating in the scenario planning process) perspectives of the organisational environment, by increasing flexibility in thinking, to ultimately ensure the survival and success of the organisation (Schoemaker, 1993; van der Heijden et al., 2002). SP helps achieve this by intervening in the strategic management process (Hodgkinson and Healey, 2008). The key to such a strategic intervention lies in guiding teams to "design scenarios so that managers would question their own model of reality and change it when necessary" (Wack, 1985a, p. 84). The driving force behind desiring to challenge and change these models of reality (i.e. mental models) is due to the strong and often cristalised presence of cognitive biases that stem from regularly referenced heuristics for decision-making. Biases create boundaries to our perceptions of reality, and limit the scope of our rationality, awareness, and creativity (Simon, 1972). It is from these limitations that insufficient awareness is given to the environmental uncertainties. This bears consideration only because we hold the general assumption that environmental uncertainties will change as the future emerges (Balarezo and Nielsen, 2017). By remaining inattentive to such 
environmental factors, organisations can suffer from insufficient planning and inflexibility, therefore failing to successfully navigate their emerging future.

At this point in the field's development, given the variety of schools, definitions, and the attempts to unify these areas within an inherently pragmatic methodology that allows for continuous modifications, it seems appropriate to establish a typology of the potential dimensions for a SP intervention. We disagree with Spaniol and Rowland's (2018b) claim that any possible attempt at future typologies (and theories) to help establish a foundation to the field of SP are little more than contributions to the "chaos" that many proport to plague the discipline. Rather than paradoxically distancing the literature from a potential foundational theory by developing a new typology, the efforts in this paper can be seen as the next logical step in the scientific validation of a field's development. First, each former typology either attempted to address a specific set of dimensions within the scenario process, or encompass perceived missing shared perspectives from extant typologies. Such efforts should not be seen as divided and mudding the waters, but rather multiple, corroborated contributions where each add yet another piece (or several) to the SP puzzle. A puzzle that is being constructed from the most salient pieces towards the more obscure, as they are discovered, rather than by traditional methods which establish the boundaries (e.g. edge pieces) first. Therefore, leaving us not so much unclear on the functional parts, but unclear on the final form. Second, many typologies (e.g. van Notten, Rotmans, van Asselt, and Rothman, 2003; VRVR typology) have combined existing typologies and expanded them. These are precisely the efforts any developing discipline requires in order to benefit from the many discoveries. Expanding does not necessarily create distance from the foundation, but rather embodies the very expression of scientific exploration and unification. Typologies help formalise the existing and potential factors of a discipline. By establishing a system of classification that can be intuitively and logically followed, a typology can aid efforts in the field. Third, the purpose of the CSI typology is specifically to guide bestpractice intervention efforts. No single SP method is going to fit every intervention. Understanding which method is the best fit for a given internvention will depend on the particular dimensions of the organisation's SP profile. A "profile" is the unique set of CSI typological dimensions that plot the details of the chosen SP intervention. For example, if a facilitator is developing an intervention, and they desire to have both decision makers and stakeholders as part of the SP practitioner group, then they can reasonaly expect to be working with a heterogeneous group (and therefore not a homogeneous group), and will probably be using at the very least, a participatory method of data generation. If the organisation is motivated to hold a SP intervention in order to discover tranformative options to their policies, then the group has a clearer picture of the organisation's willingness to implement tranformational impacts, whether in structured or unstructured ways. The CSI typology aids the practitioners in identifying such dimensions of their profile. This is a major leap forward from the typical ad hoc method of discover-as-you-go.

A typology can help strengthen the field's foundation, "create useful heuristics, and provide a systematic basis for comparison" (Smith, 2002, p. 381). The earliest generalised SP typology was published in 1980 by Ducot and Lubbens. Each successive typology developed with a different focus, using a different language, with occasional overlapping dimensions. We agree with Millet's (2003, p. 19) statement that, "the next generation of scenario tools should not only combine previous methods, but also actually blend them into a more comprehensive methodology," and apply this to our efforts with extant scenario typologies, the body of theory, and real-world applications. The aims of this paper are to 1) present a comprehensive typology for SP interventions that offers practitioners clear profiles for guidance towards fundamental changes in perceptions and organisational actions, 2) aid scholars in empirically exploring the necessary dimensions of SP interventions, and 3) join in the effort of building a stronger foundation for the field of SP - and by extension, futures and forecasting methods at large.

\section{Limitations}

The typological approach has well-known flaws. What sets typologies apart from taxonomies is that the dimensions of the former often represent conceptual rather than empirical knowledge (Smith, 2002). The drawbacks are that a typology's dimensions may be neither exhaustive nor mutually exclusive, use ad hoc criteria, lack explanatory and predictive qualities, and suffer the problem of reification (Bailey, 1994).

\subsection{Dimensions}

Unlike taxonomies, typologies do not necessarily elicit a particular order, depending on the purposes of use. The order can determine the ways in which the information is relayed and utilised. This is particularly true in the hard sciences, with the use of taxonomies, but in the social sciences a different method of use is possible (Riede, 2006; Smith, 2002). As opposed to biological classifications, cultural materials can emerge through a form of 
organic evolution, and as such, be divided on any number of factors. 2 The four, broad CSI typology dimensions (i.e. sections) can have an ordering effect, which support both planning and process efforts, but can also abandon any temporal necessity when used as an aid for research development or retroactively as a systems check. The more nuanced dimensions (i.e. within sections), however, do not necessarily have an ordered path, and are there to show the importance of different critical dimensions. Therefore, the CSI typology can be used as a guide for ordered efforts or as a guide for necessary dimensions, depending on the facilitator's needs.

With these adaptable criteria established for the applicability of the CSI typology, so too does this same adaptability extend to the individual dimensions. Depending on the dimensions, the relationships between them can be dependent, independent, interrelated, or mutually exclusive. Rather than treating this as a drawback, the adaptability of dimensional relationships strengthens the design by creating a road map of available and unavailable options, based on the dimensions chosen to develop your SP profile.

Some of the dimensions of previous typologies do not fit into the

discrete dimensions of the CSI typology. Instead they describe a selection of dimensions that comprise a particular SP profile. This is the case with Wilkinson and Eidinow's (2008) typology (WE typology), which draws on existing environmental scenario projects to develop three themes: problem-focused, actor-centric, and reflexive interventionist or multiagent based (RIMA). The three themes capture a series of CSI dimensions to create three wholly different profiles, with the purpose of capturing the epistemologies that underpin SP. Therefore, the three profiles of the WE typology are discussed at length in the last section of the paper, where the CSI typology is applied, in full.

Chermack (2018, p. 50) acknowledges that "it is generally difficult to engage in intervention research when the intervention (scenario planning) is usually customized, methods are varied as well as the timespans and contexts of different scenario projects." However, as Chermack points out, many comparably complex disciplines have advanced in similar fashion, and charges that the discipline of SP needs researchers to tackle its difficult design in order to increase credibility and advance the discipline. To this end, we acknowledge that the CSI typology may commit similar efforts as previous typologies, by inadvertently creating broad dimensions, as time and further evolution of the field may prove. As with any system, the evolving process inherent in SP will necessitate regular reviews of any existing typology. Further nuances and new dimensions (i.e. puzzle pieces) have the potential to emerge over time. As a pragmatic model, it would only be appropriate that regular reviews of existing typologies are made. This is the motivation behind the "Comprehensive" title, rather than "Complete". A comprehensive typology presents the fullest picture, to date, for assessing a SP intervention, adds beneficial knowledge to the field that will prove largely resilient with time, and serves as a catalyst for future discoveries of potentially new dimensions. Further, if we have done our job successfully, then the CSI typology will have the capacity to serve as a foundational typology from which further dimensions can branch.

\subsection{Criteria}

When working with conceptual rather than empirical data, the methods for building a typology can follow more intuitive than explicit lines of reasoning. In response, this issue is addressed through a multilevel, developmental approach, which we believe brings the greatest level of validity and robustness to the construction of SP typologies. Beginning with a bottom-up approach, the CSI typology was first outlined using the dimensions of all pertinent SP typologies. Commonalities were grouped, and differences were separated. All existing dimensions were incorporated. Next, using Spaniol and Rowland's (2018a) approach, the extant body of research was layered to discover overlapping SP elements either suggested or utilised in interventions. This created a skeletal framework for the CSI typology. After this, outlier elements (those practices that did not have wide use) were measured against the developed CSI typology skeletal framework, to determine whether they were dimensions or techniques (Bishop et al., 2007). At this point, we used Smith's (2002) typological approach, which borrows from the traditional taxonomical method, and reviewed empirical work to increase the validity and robustness of the CSI typology. Empirical data were not an available resource for many of the earlier typologies, therefore giving the CSI typology additional novel support. Moving into the future, as the body of empirical work expands, these data should serve as stronger sources for typological development.

2 The theory is borrowed from Oscar Montelius' and Hans Hildebrand's "Swedish typology", which suggests that culture and biological life develop through analogous forms of evolutionary process, and typologies are possible for both, but do not necessarily need to take the same forms (Riede, 2006). 


\subsection{Explanatory and predictive qualities}

Godet and Roubelat (1996, p. 1) highlight the fact that organisations must "not only be reactive and preactive, but also proactive." In agreement with the authors, the CSI typology serves to facilitate all three efforts. There is the utilitarian use of presenting a map of dimensions inherent in an intervention. From a retrospective function, the CSI typology can help experienced facilitators plot the profiles of previous SP interventions to learn from and improve methods. As Wack pointed out when retiring from Shell, one of the most difficult things to change are the mental maps (i.e. models) of managers (Chermack, 2011). Mintzberg (1994) echoes these sentiments, stating that this is possibly even more difficult than building the scenarios, themselves. If a former SP intervention yielded little change for the organisation, for example, the CSI typology could help reveal hidden friction points, stickiness, or lost resources, by providing a map against which methods used in the intervention could be plotted. By forcing users to explicitly declare the dimensions of their SP profile, they are quickly faced with the primary inconsistencies. Going further, causal indicators can be identified by logically linking the path of outcomes from the dimensions of the unique profile. Using the example above, failures could be caused due to whether the decision makers were part of the scenario group (increasing the probability that their mental models were challenged), whether the quantity of scenarios was too few (perhaps from low involvement and too little information) or too many (resulting in information overload, leading to strategic inertia), or perhaps the institutional resources were limited, thus leading to poor use of open institutional conditions. Any number of explanatory elements can be learned from a retrospective look. From a prospective, predictive function, a typology can help facilitators anticipate the parameters of a particular profile, and act "as a checklist when analysing scenarios" (van Notten et al., 2003, p. 439). A typology can also aid researchers in studying the different schools of SP, given their research goals, questions, and methodology.

\subsection{Reification}

The final point is the problem of reification. Typologies that suffer such failures are traditionally found in more conceptually-based practices, such as policy, religious, and moral development. These practices are problematic to the typological method because there exists little consensus and/or poor definitions. SP interventions,

however, do not suffer such extreme vagaries in knowledge and practice. The consensus of the literature, results of empirical work, and developments of realworld applications lend themselves to clear definitions (e.g. quantitative and qualitative data) and divisible, conceptual dimensions (e.g. planning, development, outcomes).

Furthermore, the CSI typology does not attempt to classify such contentious abstractions as personality, which are outside the scope of this typology (see Hodgkinson and Healey, 2008). This is mainly due to the diminishing support of such personality theories as the Five Factor Model and Myers-Briggs Type Indicator, and similar, which have shown to be less reliable, valid, independent, and comprehensive than previously thought (Gardner and Martinko, 1996; McCrae and Costa Jr, 1989; Paul, 2004). But this is not to say the unique qualities of each practitioner are not vital to the success of an interventions. Cognitive factors, as they pertain to a SP intervention, are discussed at length within various dimensions across the CSI typology, both individually and jointly.

\subsection{Communicative power}

van Notten et al. (2003) argue that a potential limitation to their typology is that the tension between striving for detail and attempting to achieve comprehensiveness may lead to the deterioration of their typology's

communicative power. This recognition of static between the two functions may explain the more simplistic and elegant approaches to the other typologies. Given the extensive practice of SP, and the lack of robust evidence on their true effects (whether as a business-support method or mental models challenger), we believe the field could benefit from a typology that errs on the side of comprehensiveness, even if it means losing some of the elegance.

Another drawback to typologies is that they may be limited in

scope. As van Notten et al. (2003) offer, classifications for businessoriented scenarios would be hard pressed to also acknowledge the differences that are fundamental in, say, macro-economic and environmental scenarios. To address this issue, the CSI typology has been compared against the prevailing schools of scenario planning, Chermack's theoretical design, as well as over 200 scenario case studies that cover a heterogenous selection of disciplines and purposes (management, economics, environment, policy sciences, space exploration, etc.) to ensure its broad applicability. One sector we were unable to more fully explore for applicability was the private sector, and this was largely due to protections in place on sensitive materials. 


\section{Method}

To discover all possible scenario planning typologies, the broadest search criteria were used. The following sources were searched: EBSCO, ProQuest, Emerald, JSTOR, JURN, Google Scholar, Research Gate, University of Strathclyde Library, Web of Knowledge, and Scopus.3 Dates were restricted to the 20th and 21st centuries, up to March 2019. The publication formats of book, journal, dissertation, thesis, conference proceeding, and periodical were included. The search terms "scenario typology", "scenario planning typology", "scenario method typology", "scenario intervention typology", "scenario school typology", along with substituting "taxonomy" for "typology" in all previous phrases, were used, and all attempts were made to search all languages, not just English. The search criteria returned 4450 publication results. Fifty-one publications specifically included a SP typology. We eliminated publications that referenced other typologies - instead of developing their own -, typologies for specific fields (e.g. education or transport), and typologies for a specific stage within the larger SP process. Eight typologies emerged from this search that were developed for more ubiquitous SP applications. A larger number of scenario reviews and case studies also serve to inform the parameters of the CSI typology.

The eight typologies offer brief elaborations, presented as either a simple matrix (Ducot and Lubben, 1980; Heugens and van Oosterhout, 2001; Wilkinson et al., 2013) or as three semi-reducible themes (Börjeson et al., 2006; Pulver and VanDeveer, 2007; van de Riet et al., 2008; van Notten et al., 2003; Wilkinson and Eidinow, 2008). These eight typologies will be referred by the following titles in this paper: BHDEF typology (Börjeson et al., 2006), DL typology (Ducot and Lubben, 1980), HV typology (Heugens and van Oosterhout, 2001), PV typology (Pulver and VanDeveer, 2007), VAV typology (van Der Fels-Klerx et al., 2002), VRVR typology (van Notten et al., 2003), WE typology (Wilkinson and Eidinow, 2008), and WKM typology (Wilkinson et al., 2013). Though the WE typology was developed using mainly environmental scenarios and the VAV typology was developed for the specific realm of policy within transport infrastructure investments, the authors state that their typologies are aimed at scenario practitioners, in general, and make a compelling argument for the broader applications of their dimensions, and as such we find both typologies offer invaluable information.

The CSI typology incorporates all previous typologies, pertinent to this classification, along with additions that reflect previously unrecognized dimensions and emergent topics. All past typologies offer insightful and novel perspectives on SP interventions. However, a common practice in the present typologies is to create overlybroad categories. This is an understandable method to initiate in a developing system. In order to capture as much of the field as possible, but preserve intuitive levels of comprehensibility, broad categorisation can be necessary. This effort has the consequence, of course, of grouping several dimensions together that may later prove to be too disparate. These points are addressed in the explanations of each dimension.

The first major obstacle in developing the CSI typology was understanding each author's use and purpose behind their dimensions. Sometimes it is the case that the same dimension is used across different typologies, with different meanings. Other times different dimensions are used across the typologies, but with similar or identical meanings. An example is the dimension "normative/normativity". The DL typology defines normative as the explicit accounting of the observer's preoccupations and interests, or "value-mindedness" (p. 53) from practitioners. The HV typology defines normativity as levels of involvement (passive or active) reflected in an organisation's interests and expectations in scenarios. The VRVR typology uses the term normativity to describe scenarios that include probable or preferred outcomes. And finally, the BHDEF typology uses the term normativity to describe how a specific target is reached within a scenario, presenting either a preserving path through efficiency, or transformative adjustments. As it worked out, the VRVR and DL typological uses of normativity were comparable and combined to help define the "Normative scenarios" dimension, whereas the HV typological use provided two sub-categories of normative dimension, and the BHDEF was unique enough to inform a new dimension that reduces into divisible categories.

The second obstacle was determining whether an existing typology's dimension was narrow enough to serve as a single CSI typological dimension, or broad enough to be re-purposed. The dissection of dimensions resulted in one of two inclusions in the CSI typology; Either the original dimension is maintained within the new typology, or the original dimension is used to describe a profile. We were motivated to preserve the existing vernacular wherever possible, to improve the synthesis of the various bodies of research. However, the terminology for some of the dimensions in past typologies did not go far enough in capturing the meaning of the CSI typological 
dimension, to which it was applied. In these few cases, we therefore provided new terminology in an effort to better define the dimension.

The CSI typology begins by modeling the structure of the VRVR typology. This method was chosen for two reasons. First, the VRVR typology is the most extensively developed of the existing typologies. van Notten et al. (2003, p. 424) recognised that existing typologies did not "sufficiently capture the diversity in contemporary scenario analysis", and instead developed their own extensive VRVR typology that breaks from the more simplistic designs of the others. Second, van Notten, et al. tested the robustness of their VRVR typology against 18 scenario projects selected from 70 case studies - spanning the disciplines of management, economics, environmental, and policy sciences - showing the broad applicability of a multi-themed typology.

The CSI typology is divided into a temporal heirarchy of dimensions. The broadest dimensions are "sections". Sections are thematic divisions of SP that encompass the preparation, scope, content, and follow-through of the process. Each section is divided into different "characteristics". Each characteristic is further divided into different "categories". Some categories are divided into different "sub-categories", which are the most focused dimensions of the CSI typlogy. Depending on the dimensions, the relationships between them can be dependent, independent, interrelated, mutually exclusive, or unrelated. Table 1 presents the full CSI typology - divided into four broad sections, with a total of 22 characteristics, 91 categories, and 30 sub-categories. A full SP profile should include all sections, but does not require all characteristics, categories, or sub-categories to be represented. The specifics of an organisation, a facilitator's chosen SP method, and available resources will all determine which dimensions are available and necessary. The CSI typology was tested against the scenario case studies used in the extant typologies, the leading schools of SP, and an additional 36 SP interventions across a variety of disciplines (see Appendix A).

[insert Table 1 about here]

Ducot and Lubben (1980) suggest that by aligning scenarios with the cross-selection of dimensions, the resulting scenarios will be more resilient to methodological criticisms, and by extension, more credible. These cross-selections create unique SP profiles. Whereas the WKM typology offers 4 potential profiles, and the DL typology offers 27 potential profiles, the CSI typology has the ability to map out more than one million unique profiles.

\section{CSI typology}

When no definitive model can be specified for predictive purposes, but key factors can be identified, which can develop into structurally different futures, then we are working with structural (Dreborg, 2002), or qualitative (Eriksson, 2004), uncertainty. As such, this type of uncertainty is best served by SP methods which help practitioners navigate such structural changes, where flexibility, adaptation, and exploitation can be developed (Biggs et al., 2007; Eriksson, 2004). The future is a conceptual space, and scenarios can act as transitional objects to take us from our perceptions of the here-and-now to our assumptions about the there-and-then (Wilkinson, 2009). The CSI typology was developed to help facilitators and practitioners identify and work with these uncertainties.

\subsection{Section 1: Project goals}

The first section is concerned with answering the question, "What do you want to do?" This section presents the elements that must be addressed to set the agenda for a SP intervention. Summarising the general perspectives from schools of planning theory, Dreborg $(2002$, p. 4) states that "in practice, planning is more reactive than goal-orientated in character," and this is due to cognitive limitations from bounded rationality. To help counter such limitations, practitioners should take the necessary time to understand and articulate their organisation's goals on the various dimensions within Section 1. There can be scenarios that aim for a single, unifying goal, as was the case with the branching scenario workshops for the local governance of the North West Tasmania region, where the workshops aimed for "[articulated] actions to achieve the commonly-held goal of regeneration," (Tasmania Case; Cairns et al., 2017, p. 9). Other SP interventions have multiple goals which require a number of complementing efforts through the process. The project goals can be framed through eight characteristics. Each characteristic addresses a different, yet complementing aspect of the question, and helps frame the intervention for the practitioners and facilitators. It is in this preparation section that Chermack's (2011) fifth domain of his SP theory, "Leadership Theory", finds its first footing. "Leaders drive virtually all 
aspects of organizational life, including policy, human resource practices, structure, and compensation, among many, many others" (p. 53), and it is through the strength of an organisation's leadership that success will be found through the SP process.

\subsubsection{Epistemology}

"What level of engagement will the organisation take?" When assessing the organisational goals for a SP intervention, Heugens and van Oosterhout (2001) suggest making clear the epistemological characteristic of the scenario foundation. From the HV typology, we include this category, which frames scenarios as either taking a Cartesianor non-Cartesianpath. A Cartesian approach to scenario development is a purely cognitive practice designed to facilitate conversations which speculate about the future, whether by challenging mental models or expanding knowledge, and give more focus to the process than the outcomes (Biggs, et al., 2007). An example of this is the Massive Scenario Generation (MSG) model (Davis et al., 2007). The MSG model serves to enrich a planner's mental library to "help guide planning under uncertainty" (p. 51) in the moment of a potential future disruption. This effort is what the WKM typology calls "seeing", where scenarios are not used to generate strategic options, but rather to provide illustrative examples of plausible futures. As first round scenarios, Wack (1985a) referred to these as first-generation or learning scenarios. Wack takes this concept further when he states, "If the scenario process does not bring out strategic options previously unconsidered by managers, then it has been sterile" (p. 10). van de Riet et al. (2008) refer to these as process-focused approaches, where the primary purpose is either to achieve consensus or broaden the practitioner's thinking. Non-Cartesian scenarios bring together the cognitive with action-oriented efforts, and link strategy formation with implementation. As second round scenarios, Wack (ibid) considered them decision scenarios. The WKM typology calls these "seeding" scenarios, where creating actionable options can illuminate a future that otherwise may not come to fruition. van de Riet et al. (2008) refer to these as content-focused approaches, with the aims of developing and evaluating policy options while identifying highly uncertain/highly impactful events. The Global Trends 2030 scenarios used this approach by specifically sourcing feedback in the second half of the project to inform preparatory action in the near future for EU institutions (de Vasconcelos et al., 2012).

\subsubsection{Control}

"What control can be assumed?" This dimension is an addition to the existing typologies. A key driver in understanding how to manage the narratives within a SP intervention is in understanding the role the organisation holds within the external environment. The organisation either sees itself as holding a passive, reactive, preactive, proactive, or reflexive position. Organisations with a passive perspective see themselves as independent of the external environment. They take no active or effecting role, nor do they see themselves being heavily affected by environmental factors. Godet and Roubelat (1996) refer to these perspectives as ostriches, playing on the metaphor of sticking their head in the sand and essentially blinding themselves to any external activities. It may seem farfetched to assume an organisation would participate in a SP intervention, only to hold a passive perspective on control. However, this is precisely the reason attributed to some failures in past interventions. The SP team held one view of the organisation's relationship with the external environment, only to be countered, later, in their beliefs by the decision makers, who revealed a completely different perspective, resulting in no action or change being adopted. This was potentially the case with implementation stage of the "Netherlands in 2030" project (Omgevingsbeleid, 2000), briefly discussed by van Notten et al. (2003). Reactive organisations are past-oriented. Present states are less desirable than some form of the past, and perspectives may favour a backwards looking perspective. A positive expression of this perspective are firemen and the development of fire safety protocols and regulations (Godet and Roubelat, 1996). Reactive perspectives are held in risk-management scenarios, such as the Federal Emergency Management Agency (FEMA) disaster scenarios, developed for internal and cross-discipline response to natural disasters (FEMA, 2018). Preactive perspectives are forward looking, where the organisation holds some form of control within, to navigate external forces that are out of their control. Contingency planning, such as insurance policies, are products of preactive perspectives. For both reactive and preactive perspectives, organisations look to adapt to changing external conditions (Gordon, 2011). Proactive perspectives are forward looking as well, but see the organisation as an active player that can provoke change and design the future around their goals. Reflexive perspectives see circular relationships between the external and internal environments. The external environment affects the abilities, resources, and perceptions of the organisation, and in return, the efforts of the organisation affect the functioning and perceptions of the external environment, creating a feedback loop (Soros, 2013). Proactive and reflexive perspectives hold the potential for the organisation to intervene on future conditions for the purpose of creating better conditions (Gordon, 2011). 


\subsubsection{Value/reality}

"What will be the value/reality relationship?" The next dimension highlights the desirability included in developing scenario states. Scenarios include descriptive, normative, or dynamic categories. Descriptive scenarios present possible futures without accounting for the level of desirability of those outcomes. They are an exploration of possible outcomes which can include baseline, reference, and non-interventions (van Notten et al., 2003). The VAV typology considers these contextual scenarios. The DL typology further divides descriptive scenarios into hypothetical and plausible sub-categories. Hypothetical scenarios offer greater explorative options since they can expand the farthest from reality. They hold weaker causal relationships and credulity, allowing for greater exploration of variables and relationships. Schultz (2015) refers to these as crazy futures, and even goes so far as to consider these the most useful in the SP process. This can be beneficial when practitioners would like to avoid the "unconscious neglect of unlikely or undesirable possibilities" (Ducot and Lubben, 1980, p. 52). Plausible scenarios introduce factors represented in the organisation's environment and can include probability statements. Plausible descriptions, however, should not be confused with the validation efforts of plausibility. Though related, they are not the same, and if nothing else, illustrate the obfuscating nature of SP terminology in the extant literature. Plausibility is further discussed in Section 3.

Normative scenarios represent a type of "value-mindedness" (Ducot and Lubben, 1980, p. 53) guided by the concerns, interests, motivations, desires and occupations of the group (van de Riet et al., 2008). These scenarios can include prospective, strategy, policy and intervention scenarios (van Notten et al., 2003). The school of $L a$ Prospective takes a normative/deterministic approach to scenarios (Wilkinson and Eidinow, 2008). The HV typology defines normative scenarios as encompassing a continuum between the two extreme subcategories of active and passive. Normative scenarios with an active narrative are developed to stimulate action through strategic conversations evaluating policy and practice (Biggs, et al., 2007). This can be taken in hand with nonCartesian approaches. At the other end of the spectrum, passive involvement with normative scenarios are generated by content taking an observational role in the process, and using the SP intervention as a method for stimulating strategic conversations around norms (Heugens and van Oosterhout, 2001). This dimension can align with the Cartesian approach, but with a purposeful normative focus. Most agree that it may be impossible to create a scenario free of normative inclusions, if nothing else, at the implicit level. Ducot and Lubben (1980) recognise the option for a combination of descriptive and normative elements within, known as dynamic scenarios. These scenarios combine the value-mindedness of normative elements with descriptive realism to create richer scenario involvement. Examples of descriptive, normative, and especially dynamic scenarios can be found from scenario projects conducted through The Millennium Project. The long-rang "Millennium 3000 Scenarios" illustrate key features of dynamic scenario development (Glenn and Gordon, 2000). Experts identifiedand ranked the top norms, around which to form the resulting scenarios. The scenario process linked the top ranked norms with explorations of uncertainties that used an experimental method, where the scenarios drove the model. Scenarios were built to identify actions necessary to address the stated Global Challenges.

Though dynamic scenarios may initially give the impression of being the best of the both worlds, they can, in practice, result in even greater frustrations if goals and boundaries are not well defined at the start, or power dynamics dominate within the group(s). An example of a scenario group's value/reality relationship clashing during an intervention can be found in Cairns et al. (2017) "Tasmania Case". The goals of the facilitators were to stimulate conversations, challenge norms, and prompt articulated action. The initial interviews and workshop were well attended, which generated challenging conversations, cross-disciplinary agreement, and consensus on the issues. However, in the latter half of the SP intervention, practitioners failed to fully engage with the actionable part of the intervention. They fell back on their norms in the end, and shifted responsibilities, thus failing to move forward with any of the potential changes they had hoped to engage.

\subsubsection{Vantage point}

"Where is the starting point?" The vantage point determines the originating point of the scenario timeline(s) (van Notten et al., 2003). This characteristic is divided into to three categories: forward-casting, backcasting, and bi-directional. Ducot and Lubben (1980, p. 51) suggest the use of hypotheses to guide the direction of the vantage point: "given the causes, what are the effect?", "given the effects, what could have been the causes?" Though the resulting scenarios will present storylines that view time as linear, the strategic conversations that take place within a SP intervention can require practitioners to work with time in multi-directional and iterative manners (Wilkinson, 2009). Ducot and Lubben's (1980) early typology is instrumental in developing the groundwork for this characteristic. To help illustrate some of the more abstract dimensions of their typology, the authors developed a series of conical figures, which are reproduced as guides within this paper (Figs. 1 and 2). 
Forward-casting scenarios look for the effects (future) of a suggested set of causes (past and present) and set the present as the starting point to the strategic conversation. Often known as exploratory scenarios - using "the present or recent past as a starting point and [exploring] how the future may develop under different sets of assumptions" (Biggs et al., 2007, p. 3) - which utilise future inferences (e.g. trend analysis) and/or inductive reasoning. They build from the present state of affairs, identifying originating causal sources, and allowing for hypotheses of what effects could develop (Fig. 1a). Ducot and Lubben (1980) represent the scenario space within a cone that expands from causal sources into greater plausibility (as a function of uncertainty) as it moves towards the effects. Analyses can be explorative, both quantitative and qualitative, setting the stage for later hypothesis testing (Börjeson et al., 2006). One of the most common types of forward-casting scenarios is likely futures. The PV typology describes scenarios which offer likely futures to contain quantitative models, with established trends of the past that act like road maps into the future. Likely future scenarios more commonly hold to norms - and consequently are absent of disruptive events -, and include predetermined factors - events that have enough inertia within the system to unfold predictably over the projected time period (van der Heijden, 1998). These scenarios can be robust scenarios (through model fitting exercises), but also limited in scope due to the parameters of the models and limits of purely quantitative data. Therefore, narrative descriptions can complement the descriptive models, creating a richer scenario story (van der Heijden et al., 2002). It is worth noting, though, the prophetic words of Herman Kahn, "The most likely future isn't." The BHDEF typology expands on the predictive quality of forward-casting scenarios with the use of what-if scenarios. A particular event, or group of events, are assumed to occur and scenarios are built around this assumed skeletal framework. These scenarios can include predictions (often in the short-term) of future events believed to have the greatest importance for the organisation. The focus is on plausible events, rather than most likely or most desirable. Incasting is a form of what-if scenario development (Bishop et al., 2007). Participants read pre-drafted scenarios - usually extreme versions of alternative futures - then are tasked with describing the impacts of each future on a series of predetermined domains such as education, industry, technology. A popular focus for what-if scenarios is disaster preparedness. By combining quantitative scenario analyses with high impacting-high uncertainty driving forces, what-if scenarios have been used by the Intergovernmental Panel on Climate Change (IPCC) to understand the potential consequences of global warming and greenhouse gas emissions and potential mitigating efforts (de Coninck et al., 2018), and the "Arctic Council's Arctic Marine Shipping Assessment" to "identify the major uncertainties that would be critical to shaping the future of Arctic marine activity to 2020 and 2050" (Ellis and Brigham, 2009). What-if scenarios were also used to inform emergency protocols within the Department of Interior (DOI) that were utilized during the Deepwater Horizon oil spill (Machlis and McNutt, 2010). However, a series of disastrous failures in both prevention (proactive) and emergency responses (reactive) brought to light the failures that can come from poorly designed SP interventions, particularly ones that suffer from political interventions, homogeneous participation, and sticking too closely to past norms (Leschine et al., 2015). In response, the DOI established the Strategic Sciences Group two years later with the purpose of compiling "strategic scientific information and expertise" to "rapidly assemble teams of experts to construct interdisciplinary [science-based] scenarios of environmental crises affecting DOI resources" (DOI, 2012).

Backcasting scenarios develop from the opposite direction, which are prescriptive in nature, using deductive reasoning, with anticipatory analyses (Biggs, et al., 2007). These scenarios focus on a future event and build a logical, storied, flow back to the present state to help determine the path needed to reach the future event (Bishop et al., 2007). The DL typology suggests that anticipatory - or effectuality - scenarios can begin with multiple future-based hypotheses from which the story is built (Fig. 1b). Two popular methods for constructing backcasting scenarios are to envision ideal and crisis focused futures (though there are an uncountable number of other methods). Idea future scenarios are built through consensus on the type of future to aim for and identified trajectories to reach that future state (Pulver and VanDeveer, 2007). The La Prospective school of preferable scenarios coincide with this dimension. Eriksson (2004, p. 169) refers to these as visionary scenarios, though the methods tend to "focus on the future structure of the planning entity itself, typically allowing the external world to be rather sketchy". Ackoff's (1981) reference scenarios are a version of this type, where projections of the future are made assuming no disruptions or exogenous changes, and include interesting and provocative narratives that show the types of internal changes necessary to avoid problems. Crisis focused scenarios are only lightly touched upon in the PV typology as a "particular future to avoid" (Pulver and VanDeveer, 2007, p. 5). However, the practice of crisis awareness in scenarios, for the sake of avoidance or survival, is a common practice. FEMA regularly use disaster scenarios coupled with role playing exercises (i.e. tabletop exercises) to test procedures and practices, build critical community relationships, and trouble-shoot issues that arise during scenario workshops (Cooper and Block, 2006; FEMA, 2018; USFA, 2018). 
Several sources also describe a blending effort of both forward-casting and backcasting within a SP intervention, known as bi-directional scenarios. The DL typology describes these scenarios - called mixed - as having multiple points from which to develop hypotheses, which require practitioners to use both causality and effectuality reasoning. Ducot and Lubben (1980) illustrate bi-directional scenarios with their overlapping cones of plausibility, recreated in Fig. 2. Bi-directional scenarios can be mid-mixed, where hypotheses of past causal sources and future developing effects are developed from midpoints within the scenario's relevant period (Fig. 2a), or end-mixed, where scenarios blend the efforts of causality and effectuality relations developed in the exploratory and anticipatory scenarios (Fig. 2b). The present state serves as a starting point to identify future end-state effects, while conditions that can cause various end-states are developed in the opposite linear direction, creating additional sequences (Ducot and Lubben, 1980). The PV typology presents hedging scenarios for bi-directional scenario development. Hedging scenarios attempt to capture the full range of future alternatives. The purpose is to ensure that decisions made today will result in the best outcomes for the organisation across a range of plausible events. The other sub-category reflects a selective process in scenario development. Dortmans (2005, p. 274) explores the benefits of linking forward-casting and backcasting techniques when faced with a "dynamic strategic planning environment". Using the Defence industry for backdrop, Dortmans uses established trends to base projected forecasts of evolving futures. These are considered within the context of strategic goals of the organisation, from which backcasting is based. Together, migration landscapes are developed within to provide optimal pathways of transition from present to desired future(s).

\subsubsection{Motivation}

"What is the motivation?" Scenarios serve to move an organisation into the future with, hopefully, more attuned foresight. This foresight comes from one of two possible motivations. Preserving scenarios present the most efficient paths towards a future target. The idea of efficiency can be operationally defined in terms of any given resource (economic, human, spacial, time, etc.). According to Wilkinson and Eidinow (2008), when the target/goal can be achieved within the existing structure, preserving scenarios are the focus. Quantitative measures, such as optimising modeling, or qualitative measures, such as unstructured interviews, can be part of the process (Börjeson et al., 2006). SP interventions motivated for policy support will often take this path (Biggs et al., 2007). Preserving scenarios are helpful, for example, when working through disaster preparedness policy, where a shared target is the speedy rescue of all citizens in danger, reinstatement of electricity, gas, and clean water during and after a natural disaster. Preserving scenarios help first responders understand the potentials of a disaster environment in order to utilise their existing channels of communication and equipment in the most efficient ways possible during rescue efforts, in order to minimise/eliminate human death tolls. However, in the private sector, preserving scenarios can also reinforce existing norms and biases, stifling exploratory thinking and ultimately failing to challenge mental models. Transforming scenarios, on the other hand, present paths of development that reveal the potential for an organisation to change a fundamental element of its behaviour in order to either achieve targets or avoid potential crises. These categories originate from the BHDEF typology, but with additional applications. Both the BHDEF and WE typologies consider these categories normative in nature, with transforming scenarios resigned to purely backcasting efforts. However, there are a number of scenario interventions that have proven to be forward-casting in design, with transforming elements. Dortmans (2005) presents this very method in his review of the Defence sector approaches.

\subsubsection{Application}

"How will scenarios be applied?" Key to any SP intervention is determining, at the start, how the organisation wants to apply the outcomes (insights, knowledge, and stories) of the intervention. This characteristic is provided by the VAV typology, with two categories: generic and specific. Generic scenarios are developed with a general use in mind. They do not focus on a specific problem, but offer objectivelevel stories of the future that can be used by any number of sectors and organisations to help inform their own developments. Scenarios that take a long-term time horizon will often be generic in their story telling. Specific scenarios closely focus on predetermined details, such as issues in policy and practice, take a more in-depth exploration. Specific scenarios can be used to test such efforts as Dutch transportation infrastructure policy evaluation (van de Riet et al., 2008), Sweden's pursuit of crime prevention (Lindgren and Bandhold, 2003), and public school cohesion (Goens, 1999). The VAV typology acknowledges that it may also be the case that general efforts are initially made to lay the ground work for various specific paths. Though it is difficult to fully realise a priori the applicability of the scenarios that will emerge from an intervention, it is important, all the same, to understand the dimensions of this characteristic. If a scenario team can clarify their project goals (Section 1) and anticipate features of the 
scenario impact (Section 4), then they have a better chance of increasing the success of their SP intervention efforts.

\subsubsection{Subject}

"What is the subject focus?" This characteristic comes from the VRVR typology and defines the particular subject(s) of the SP intervention. The details of the subject will determine, in large part, which variables the practitioners focus their attentions. van Notten et al. (2003), provide the first three categories, issue-based, areabased, and institutional-based. Issue-based scenarios are concerned with societal issues, such as the judicial system of Sweden's scenario workshops to better understand the future crime arena (Lindgren and Bandhold, 2003), Australia's gender pay gap (Jefferson and Preston, 2005), and immigration (Migration Data Portal, 2017), but can also be concerned with what the WKM typology refers to as grandchallenges. These are issues of immeasurable scale, often with high levels of uncertainty, such as the "Global-Change Scenarios" developed for the US Climate Change Science Program (Parson et al., 2007). Area-based scenarios cover geographical areas (e.g. boroughs, regions, and borders). Institutional-based scenarios cover concerns from within the organisation. The WKM typology calls this category single-client focused scenarios, which are largely concerned with the issues surrounding a government or company. A fourth category is included, cross-based. Though van Notten, et al., mention the practiced method of blending several subjects in a single SP intervention, they do not formally include this into their VRVR typology. Sometimes the focal subject is not clear, and part of the scenario process is to determine where the practitioners' collective focus should lie. An example of this is with the "Tasmania Case" (Cairns et al., 2017). To set the agenda for the workshops, semi-structured interviews were held with a heterogeneous group $(n=81)$ of stakeholders to determine where their perceptions aligned on the critical issues. These early interviews helped determine whether the issues were outside the region (area-based), or within the culture (issue-based), and how much control could conceivably be exerted over their changes.

\subsubsection{Variable scale}

"Where is the variable focus?" Though discussed widely in numerous reviews and papers, only the VRVR typology includes a "variable" dimension (see variable mixture in Section 3). The CSI typology, however, divides the key features of scenario variables across two sections and three categories, representing the different dimensions that serve different purposes. Practitioners will focus on one or all of the following categories: external, internal, and policy.

External, exogenous variables are "those fundamental forces that bring about change or movement in the patterns and trends that we identify as underpinning observable events in the world" (van der Heijden et al., 2002 , p. 282). These variables act upon the organisation, are difficult or impossible to control, and carry the potential to impact an organisation's achievements in reaching their goals and affecting their motivation (Biggs, et al., 2007). Some examples are technological, ecological, and political developments (van Notten et al., 2003). The BHDEF typology refers to these as external scenarios, which help develop and assess policies and strategies, but can be general with broad target groups. The VRVR typology labels these macro variables, and considers them the exclusive territory of institutional-based scenarios. However, the CSI typology expands the applicability of external, macro variables to hold the potential to act upon any subject under consideration, not just institutions. By focusing on the macro level, Gordon $(2011$, p. 77) suggests that the organisation is looking to adapt to the external environment, rather than influence it, in their bid to "improve their competitive alignment with future opportunities". Internal variables are endogenous, internal driving forces that are more controllable (to an extent) and part of the organisational system, such as organisational culture, time frame, and leadership (Biggs et al., 2007; Keough and Shanaha, 2008). The VRVR typology refers to these as meso variables that encompass transactional scenarios, with factors under direct influence of the organisation (e.g. clients, suppliers, organisational culture, and interest groups). The BHDEF typology refers to these as strategic scenarios that define target factors with a range of potential consequences in order to test such things as policy impact, to ultimately inform strategic decisions. Policy variables are often focused in goal-oriented, normative scenarios, with either a content or process focus, in order to test procedures against desired targets (Amer et al., 2013; Dreborg, 2002; van de Riet et al., 2008). This is the case when using Fuzzy Cognitive Maps - a method of using causal cognitive maps for scenario development - to study and analyse foreign policy, social policies, and more (Craiger et al., 1996; Kosko, 1997; Mago et al., 2013). Policy variables play a central role in the problemfocused approach of the WE typology, where legalistic decision-making cultures associated with policy making are involved. Of course, any combination of these variables can be considered in a single intervention through multi-scale methods. Details of the project goals will largely determine which variable categories are designated for focus and exploration. An example of multi-scale scenarios can be found in the Equalities and Human Rights 
Advisor Group (EHRAG) workshops aimed at determining various forms of impact from social policies designed for citizens (e.g. remote, elderly, single home dwellers) and special interest groups (e.g. Age Scotland and Enable Scotland) with consideration of environmental factors (e.g. seasonal shifts and global warming) (Audit Scotland, 2019).

\subsubsection{Horizon}

"How far away is the future?" For every possible future point, there is a scenario discussing it. This characteristic identifies the time line for the scenarios. The VRVR typology recognises two categories, shortterm and long-term - called time scale. van Notten et al. (2003) state that short-term scales cover 3-10 years and long-term scales cover more than 25 years in the future. The VRVR typology offers a good starting point, but practice shows that further nuances are required to better capture the different scenario profiles. Shell creates scenarios ranging from 6 months to 50 years. Kahn et al. (1976) offer scenarios projected across 200 years into the future. Linneman and Klein (1979) review a sample of firms who regularly use scenario analysis as part of their planning strategies. Their surveys reveal a bimodal distribution at five and 10 years. These peak year projections appear repeatedly in the majority of the scenario reports featured in this paper. Building on such discoveries and real-world use, the CSI typology attempts to offer a more nuanced division of the horizon as short-term, medium-term, long-term, and congruent. Short-term horizons look no farther than five years into the future. Medium-term horizons focus on fairly distant futures that fall between five to 10 years. Long-term horizons take a long-range view that can reach generationally and span more than 10 years into the future. The farther into the future a scenario projects, the more general the scenario content tends to become, as a factor of uncertainty (Schnaars, 1987; Zentner, 1975). A mixture of congruent, target horizons (short- to long-term) can be found in the "Empowering Europe's Future" scenarios (Grevi et al., 2013). Beginning in the year of publication - 2013 - multiple dimension-specific scenarios plot projected paths to the year 2050. As a result, the congruent horizons offer various levels of detail for strategy development. The more nuanced implications of options for the EU are plotted against the scenarios' short-term horizons (1-5 years), and projections for global engagement are plotted against the scenarios' long-term horizons (up to 37 years) - however these latter efforts are told with more broad stroke storylines.

\subsubsection{Geographic scope}

"Where are the geographic boundaries?" The geographic scope defines the physical boundaries of interest. The VRVR typology lists two categories, global/supranational and national/local. However, these categories are further divided within the body of the literature to give a range beginning at the "global level, to supranational areas, to national, to... regional areas, and finally to local areas” (van Notten et al., 2003, p. 431). The CSI typology divides each of these geographic areas into their own discrete category - global, supranational, national, regional, and local - and includes an overlapping category, which takes into account the opportunities for scenarios to strategically focus on any combination of categories. This is illustrated in several of FEMA's tabletop scenario exercises where experts from different sectors (local to federal, private to public) work together in testing and further developing scenarios to ensure their various arenas work in a cohesive manner to expedite safety protocols before, during, and after natural disasters (FEMA, 2018). Wollenberg et al. (2000) include a necessary focus on the interrelatedness of the global, national, regional, and local overlapping boundaries when adapting SP to community forest management. van Notten et al. (2003) also recognise the occasional practice of developing scenarios with overlapping boundaries, but at the time, state that little more than simplistic efforts had been attempted. Simplistic or not, the CSI typology recognises this category as a unique profile due to its use and potential. Biggs et al. (2007) recognise that linking variables, content, and ultimately the message, in overlapping boundaries can be difficult. Some variables are geographic-specific and can lose their intended meaning when practitioners attempt up- or down-scaling of content. It is important to note that there are institutions, such as NASA, that regularly develop scenarios to include celestial events. However, their main focus is the impact and effects upon the planet, and so, fit into global-scope scenarios (NASA, 2019).

\subsection{Section 2: Process design}

The second section aims to answer the question, "How are you going to do it?" This section divides the components of the active scenario process. The title is provided from the VRVR typology, but is expanded to include additional categories. In previous typologies, there are few to no provisions to address the practitioners of a SP intervention, though they are discussed at length in other reviews and case-studies. Since there cannot be a SP intervention without practitioners, and practitioners affect every aspect of a SP intervention - from setting 
the agenda to determining outcomes - it seems appropriate to include this dimension as a necessary characteristic to any SP typology.

\subsubsection{Practitioners}

"Who will create the scenarios?" Depending on the desires and resources of an organisation, practitioners can be recruited from any number of sectors, professions, and groups. The recognised categories for the CSI typology are facilitators, problem owners, experts, employees, stakeholders, community, and cross-populations. This is one of the most important dimensions of any SP intervention. Those who participate in developing the scenarios will be the ones who gain the greatest knowledge from the intervention. This is due, in no small part, to the process of challenging the mental models of the practitioners. The practice helps "forge new common vocabulary and a rethink of the units of analysis" (Wilkinson, 2009, p. 108). This dimension highlights the third domain, "Mental Model Theory", of Chermack's (2011, p. 48) SP theory, to which he states, "Mental models encompass people's assumptions, values, experiences, beliefs, and ideas. Reperceiving the organization and its environment is thought to occur through learning that forces participants to reexamine their assumptions and alter their mental models." Due to the gravity of such learning, the general consensus is that the practitioners should include the decision makers (see Section 4).

Generally, it is necessary to have a facilitator guide the scenario process, in order to keep the project on track and guide practitioners through the multiple stages of the SP intervention. Facilitators are scenario experts, referred to as analysts in VAV typology. Bradfield et al. (2005) argue that a good facilitator can be the difference between success and failure in a scenario workshop. Facilitators help carry out and present the scenario analysis to the client. Expert opinions are sourced when specialised knowledge of the organisation, subject, a group of actors, environmental factors, and/or spacial scales are required. Brown considers an expert to be one who has a large amount of relevant knowledge, as well as "a cultivated sensitivity to its relevance which permeates [their] intuitive insight" (Brown, 1968, p. 13) Masini and Vasquez (2000, p. 57) also consider experts as those persons "with the capacity to doubt" and the willingness to accept when they are wrong, within the SP process. Lindgren and Bandhold (2003, p. 33) suggest facilitators, and other workshop members such as experts, should come from outside the organisation, "at some stages in the scenario process in order to bring external perspectives into the process." There are two sub-categories of experts, inhouse and remarkable people. Inhouse experts (i.e. intercompany panels) are from within the organisation and hold a highly specialised knowledge of key elements, applicable analyses, or otherwise bring an in-depth perspective of the organisation to SP (von der Gracht, 2008). Remarkable people (e.g. field experts, consultants), on the other hand, are experts "not normally part of the organisation's network" (van der Heijden, 1998, p. 184). Remarkable people serve specifically to challenge the business-as-usual thinking that may be implicitly employed by the practitioners in the SP intervention. As van der Heijden (ibid) describes, these are "experts who can produce an insightful 'aha' reaction from the client". Though mostly applied to remarkable people, experts, in general, are often brought in after predetermined or critical uncertainties are identified, but require more elaboration and exploration than the SP can provide (Cairns and Wright, 2018).

The VAV typology highlights the problem owners as potential members of an intervention. These are often the managers initially seeking insights for their project goals, and who will ultimately hold responsibility for the outcomes. Employees, much like inhouse experts and problem owners, come from within the organisation, and can span any level or sector - management, executives, CEOs, soldiers, administrators, and labourers, for example. Stakeholders are included in a SP intervention to ensure knowledge sharing from special-interest groups that hold a vested interest in the outcomes. Community members can also be valuable members to a scenario group, by bringing in a variety of specialty knowledge afforded those with an intimate relationship with their environment (e.g. residents and shop owners), not otherwise attainable through other methods. For example, Rawluk and Godber (2011) modified their scenario technique to ensure the Kuna Yala community members of Ukupdesi, Panama - who were historically marginalised at the time (women and youth) - were able to fully contribute in the SP project. Men, women, and youth were prevented from participating in a more traditional SP workshop settings due to cultural norms of gender and age public collaborations. In response, the authors devised alternative methods to interview community groups and then later, to integrate the whole community's input together. It is also the case that more elaborate SP interventions will recruit knowledge from some or all of these categories in cross-population efforts. These efforts often take more time, involving several group sessions, different platforms for communication, and can require extensive resources.

\subsubsection{Groups}


"How varied is the knowledge?" As important as it is to determine who will create the scenarios, so too is the variety of knowledge within the practitioner groups. The composition of the group, as much as the process, are "crucial determinants of the outcomes" of any SP intervention (Hodgkinson and Healey, 2008, p. 439). Like the previous, this category is not addressed in extant typologies, though it is discussed at some length throughout the SP literature. There are two categorical groups, homogeneous and heterogeneous. A homogeneous group is composed of a focused group of practitioners with closely defined boundaries, who may offer an in-depth perspective. Boundaries can be determined by their experience, age, profession, or education, for example. These groups can be limited to upper management/board members, stakeholder workshops, expert interviews, or any other focus-oriented group. Parson, et al. (2007, p. 65) describe a homogeneous SP group as users who "have some degree of agreement on what values they are trying to advance, what issues are relevant, and what choices are feasible, acceptable, and within their power and authority." Parson, et al. (ibid.) further elaborate that large groups can also be homogeneous when they share "their interests and perspectives, e.g., scenarios for property and casualty insurers, for organized labor in the United States, or for European environmental groups." A heterogeneous group of practitioners provides different demographic characteristics. A heterogenous group can also be referred to as a mixed group. A group of this description will provide a wide range, even disparate selection, of backgrounds (von der Gracht, 2008), cognitive styles (Hodgkinson and Clarke, 2007), agencies (Wright, Bradfield, and Cairns, 2013), education levels, relationships to the project (FEMA, 2018), expertise (van Der Fels-Klerx, Goossens, Saatkamp, and Horst, 2002), objectives and interests (Van 't Klooster and van Asselt, 2006), stakeholder and community involvement (Lindgren and Bandhold, 2003; Rawluk and Godber, 2011), and/or differently framed information (Yaniv, 2011). Stewart (2008) touches upon an important evaluation of the type of knowledge that is brought into a SP intervention. The author suggests that one of the main criteria in any SP method is to employ a "diversity of worldviews" (p. 3). Since diversity (i.e. heterogeneity) can be determined on any number of factors it is best left to be judged on a case-by-case basis by the facilitators (Hodgkinson and Healey, 2008). Homogeneity and heterogeneity are, in principle, mutually exclusive, since any deviation from group similarity is to introduce diversity, which is a feature of heterogeneity. However, these two categories could also be seen as polar ends of a spectrum, where each variation in group boundaries or demographics moves the whole of the group from one extreme form of homogeneity to ever increasing forms of heterogeneity.

\subsubsection{Data}

"What information is collected?" Though there is an immense amount of information that can be used to inform scenario development and testing, both the VRVR typology and the VAV typology offer a succinct division of data, quantitative and qualitative. Quantitative scenarios are generally discussed in terms of modelling to both develop projections as well as test for robustness. The " 25 by 25 " policy, for example, had a goal of deriving $25 \%$ of electricity and motor fuels from renewable sources by 2025 , within the US. To consider the potential impacts of renewable energy requirements, Bryant and Lempert (2010) used their scenario discovery model to guide practitioners and produce quantitative assessments from defined parameters and datasets. Quantitative scenarios can also refer to the data referenced to inform scenarios, such as the national census (Cairns et al., 2017), sales reports (Eppen et al., 1989), and even weather patterns (Pipher, 2014). The uncertainties are quantifiable within the time frame, with translatable values, such as probabilities, confidence intervals, and likelihood scores, where techniques such as Delphi (NISTEP Report, 2001) and multi-criteria decision analysis (Montibeller et al., 2006) are integrated into the SP interventions. The probabilistic approach is used with quantitative uncertainties (e.g. risk and stochastic uncertainties), when the plausible alternative future scenarios obey the same fundamental logic (Dreborg, 2002; Eriksson, 2004). Quantitative analyses are more commonly used for short-term horizons, largely due to the compounding uncertainties as time stretches farther away from the present (Fauré et al., 2017). Biggs et al. (2007) refer to quantitative approaches as hard, developing formal models where sourced information is formal, rational, and can include scientific observations. Conversely, the authors refer to qualitative approaches as soft, where personal, expert judgment and intuition, along with local knowledge and world views are sourced for data. Qualitative scenarios are used to help illustrate high levels of uncertainty, within complex situations, and use narratives to relate information (Biggs, et al., 2007; van Notten et al., 2003). Such data may include human values (i.e. norms), emotions, behaviours (Cairns et al., 2017), and historical content (Bradfield et al., 2016).

However, as is often the case with SP interventions, both quantitative and qualitative methods are used, and therefore, provide the CSI typology with a third category, complimenting. Quantitative, or semi-quantitative, information such as probabilities, trends, and national statistics can offer a strong picture of behavioural trends and differences, while qualitative information, such as first-hand accounts and creative explorations of potential outcomes between factors, can enrichen the story and help make the abstract elements more relatable, thus complimenting the story of each style. "The Trend Report" (Gros and Alcidi, 2013), commissioned by the 
European Strategy and Policy Analysis System (ESPAS), relies heavily on three quantitative, model-based analyses - two global and one scaled for the European sector. The resulting reference scenario includes 51 figure and table projections up to the years 2030, 2050, and one as far ahead as 2100. Though qualitative data were gathered from policy and industry experts, the scenario is severely limited in scope on a number of key issues, admits to not acknowledging a range of other key variables and relationships (i.e. climate change) and maintains many of the norms and trends mapped up to 2013.

\subsubsection{Data collection}

"How is the information collected?" Much like the data characteristic, the manner in which data are collected can vary with every SP intervention. The title is borrowed from the VRVR typology, with an expanded profile. At the start of any scenario process, practitioners must go on fact-finding missions, the products of which will inform the remainder of the sessions (List, 2005), though a key tenet of SP is to allow, even encourage, new information to be added and incorporated at any stage within the process (Wright et al., 2009). The VRVR typology recognises two categories, participatory and desk research.

Participatory methods include interviews, brainstorming sessions, think tanks, group discussions, surveys, workshops, Delphi-style ranking scores, incasting, role playing, storytelling, intuitive logic, visioning, and focus groups (Bishop et al., 2007; Dator, 2009; de Vasconcelos et al., 2012; Grevi et al., 2013; Teufel et al., 2013; van de Riet et al., 2008). This dimension is usually group-based work, but can also include one-on-one sessions. The VAV typology considers data gathering efforts such as surveys and closed interviews as single-way interactions, open interviews and similar as two-way interactions, and workshops or any other types of group interactive sessions as multiple-way interactions. This is an active method of data collection, and the first domain of Chermack's (2011) unifying theory of SP “Dialogue, Conversation Quality, and Engagement”. Some participatory techniques used to elicit and organise qualitative input into meaningful information can be found in the IL school. Early in the process, practitioners are asked to brainstorm about the key driving forces within the business environment, then cluster them together by closely linked causal connections (Cairns and Wright, 2018). Ramírez and Wilkinson (2014) point out that intuitive data is difficult, if impossible to validate. However, the authors suggest that the act of intuitive inquiry is not to reveal accurate predictions of the future, but to make explicit the norms, assumptions of the practitioners, and reframe what is plausible.

Desk research, on the other hand, is a passive method, that can be carried out individually. This includes such efforts as literature research, data mining, clustering, and computer simulations (van Notten et al., 2003). Dynamic modelling is one popular method of desk research. Models are developed to better understand systems complexity and how decisions can affect system behaviour. Generally, models produce either a snapshot of a current state or dynamic projections of different futures. These understandings are achieved through abstractions and simplifications of the environment (Iwaniec et al., 2014). Models can enhance scenarios, or scenarios can parameterize models, depending on the goals of the practitioners. Systems modelling has been integrated with SP to help understand "emergent, system-level behaviors that result from the interaction of variables in different subsets of complex systems," in order to explore real world challenges and solutions (Allington et al., 2018, p. 3). Agent-based modelling was used to enhance SP for the tourism industry by parameterizing human behaviour in order to reinforce strategic aspects of planning (Johnson and Sieber, 2011).

More extensive SP interventions often employ both methods of data collection. This third category is called blended. Examples of a blended method of data collection are illustrated in several scenarios commissioned by ESPAS, where trend- and impact-analyses are reported alongside creative narratives of plausible future developments. Allington et al. (2018), for example, used desk research methods, including quantitative systems dynamic modelling, with qualitative participatory scenario planning in a heterogeneous group to identify factors that could affect the future sustainability of the Mongolian Plateau, a transboundary social-ecological system. Their purpose was not to create predictions, but to "refine and formalize the qualitative conceptualizations of scenarios outlined by stakeholders, and to explore how differences between the scenarios can lead to similar or divergent futures" (p. 11).

Though data collection is typically, and for practical reasons, early in the process, there is no true completion to the inclusion of new data. There is no universal "right" length of time to collect data. The purpose is to gather enough information to successfully inform the rest of the process and subsequent strategic decisions. It is possible to have too little data, thus leaving practitioners - and by extension the organisation - blind to plausible alternatives. However, what constitutes "too little" and "too much" is difficult, possibly impossible, to quantify and will depend on the other resources of the interventions (e.g. time, cost, group size, individual members, 
goals, and perspectives). Some suggest that data collection should cease when a saturation point is reached. That is to say, when the effort to find more novel information is greater than the quality of the discovered information, then Lincoln and Guba (1985) call this saturation. Data collection should cease in its present efforts for the sake of advancing to the next stage in the process, but not necessarily for the remainder of the process (Bowen, 2008; Ringland, 2006).

\subsubsection{Resources}

"How much can be invested in the process?" The title comes from the VRVR typology and reflects the amount of available resources an organisation is willing or able to invest in a SP intervention. This characteristic offers three categories, extensive, limited, or complex resources. The first two categories are a bit self-explanatory. Extensive resources reflect such profiles as sustained numbers of practitioners/ groups over several workshop sessions, with sufficient financial backing, and available data. Limited resources can be experienced in any number of sub-categories as well. However, this category reflects a ubiquitous limitation in resources. Common examples are community-based charities, grass-roots organisations, and advocacy groups. Arguably, the resource characteristic can be divided into several discrete characteristics. However, at the sake of creating what may be an unending division of resources, a third category is offered as a means of including efficiency into the CSI typology. A complex profile of resources reflects an extensive supply of some resources, a limited supply of others, and any potential changes in availability. The Scottish Government initiative to have greater input from local constituents led to the creation of a citizens advisory group (Audit Scotland, 2019). EHRAG was established to crowdsource knowledge from third-sector organisations to improve policy development and implementation. A series of SP workshops were developed as part of the initiative. Though financial and institutional resources were readily available, attendance was low due to time and distance constraints of the practitioners. Due to the needs of their daily lives (job, family, etc.) the community members were severely time restricted, which reflected in low levels of workshop attendance.

\subsubsection{Institutional conditions}

"How much manoeuverability is available?" The VRVR typology is the only typology to includes this characteristic. van Notten et al. (2003, p. 432) note that room to manoeuvre can also be recognised as an institutional resource, but argue, "that the resources tend to be transparent whereas the institutional conditions are often more illusive". We agree with van Notten et al., and add that, arguably, any number of the characteristics in this typology could be identified as a "resource". However, this overly broad application of the definition of "resource" is not conducive to a functioning typology, and the differences between conditions and resources are great enough without resulting in extensive, reducible divisions, to include in a SP typology. Institutional conditions can be open, constrained, or structured.

Open conditions are reflected in a limitation of norms as driving factors in scenario development, and a higher freedom of creativity. Wright et al. (2013) offer a good description, "a politically-safe team learning environment and a rich learning process that stimulates creativity." An extreme example of open conditions throughout a full scenario process is provided with the "Digital Futures Final Report", from the European Commission DG CNECT (2016). In order to source insights from the broadest community $(n=3500)$, the core team used a learn-by-doing approach which resulted in altering their initial approach to one of "an informal open-ended process fueled by the spontaneous interest of participants" (p. 24). Constrained conditions can be experienced when institutional boundaries, biases, dominant views, political clashes, cultural norms, or other normative characteristics limit the exploratory efforts (van Notten et al., 2003). Constrained conditions can often be encountered within the private industry, where sensitive information is privileged, and information flow is opaque. Structured conditions offer boundaries, but still enable exploratory work. Structured scenarios may have a framework or scaffolding that was determined in a pre-process. This framework is presented alongside the project goals for practitioners to ground the scenario narratives. The "Global Europe 2050" project used structured conditions for scenario building (Commission, 2011). Their team of experts were presented with six main dimensions of the future, upon which they provided their own information in a free-mode approach with "unconstrained and unconventional representation of possible long term futures" (p. 4). The result was three highly diverse scenarios, each representing the six dimensions in an increasing order of sensitivity (i.e. uncertainty), as predetermined by the scenario.

\subsection{Section 3: Scenario content}


The third section answers the question, "What is included?" Again, the title is provided from the VRVR typology's overarching themes, with expansions. This section presents the dimensions that develop within the scenarios. If using the CSI typology for prospective purposes, the question could be reframed to ask, "What do we want to include?" or "What do we want to avoid including?" In previous typologies, uncertainty is discussed, but not incorporated as an independent dimension. Uncertainty is inherent in the process, and the key motivator for initiating a SP intervention, therefore the topic is represented in the CSI typology through two separate dimensions, one in the scenario content and another in the scenario impact sections. The section takes a look at both the individual scenario, as well as the relationship between multiple scenarios.

\subsubsection{Temporal nature}

"Which temporal outlook does the scenario present?"4 The title of this characteristic comes from the VRVR typology, and focuses at the individual scenario. The temporal characteristic presents the quality of time within the scenario story. There are three categories: chain, snapshot, and varied. Chain scenarios present a continuous storyline that illustrates developing relationships. For backcasting scenarios, these can link the end goal(s) to beginning state(s). Chain storylines can include cascading consequences which originate from a single source, as in the "US Geological Survey Appalachian (Bsal)" scenarios created to proactively prepare for a specific fungal disease (Bsal) outbreak (Hopkins et al., 2018), or time paths of development (van de Riet et al., 2008). Snapshot scenarios present a comprehensive view of a single point in time (Biggs et al., 2007; Godet and Roubelat, 1996), such as an in-depth description of the Dutch economy at a specified horizon (van de Riet et al., 2008). The VAV typology refers to these first two categories as continuous and discrete, respectively. Varied scenarios present a zoom-in-and-out effort. One form of varied scenarios shows continuous developments of events, with specific stop-gaps within the storyline that can serve as checks or bifurcation points, where in-depth attention is given. Bifurcation points, for instance, could be disruptions (Worthington et al., 2009), wicked problems (Wright et al., 2018), or catastrophes (Godet and Roubelat, 1996). Another form is presented by van Notten, et al., (2003), who mention scenarios that present mainly the end-state, with only an implicit discussion on the path towards the

end-state.

\subsubsection{Complexity}

"How many factors are represented in the scenario?" This characteristic addresses the numeracy of the features within a single scenario. There are two categories, low and high. Low complexity scenarios are more simplistic scenarios with fewer variables. These tend to present either a snapshot of a single moment in time, where, regardless of the variety of details, there is little room for elaboration, or a distant, long-term scenario where uncertainty is high which limits the amount of detail that can confidently be afforded to a scenario. High complexity scenarios, on the other hand, tend to be those that present a continuous story, with elaborative developments of relationships between factors, possibly crossing several disciplines. Though complex snapshots are possible, as well. High complexity could also refer to the number of scenarios developed from a single intervention. Kahn and Wiener's book "The Year 2000: A framework for speculation on the next thirty-three years" (1967) is an example of a project incorporating both an extreme variety of factors within a scenario, as well as several different scenarios overall. A potential drawback to highly complex scenarios, however, is that the sheer volume of information may be overwhelming, and the intended audience may get lost in the details, thus rendering the potential messages of the scenarios opaque.

\subsubsection{Integration}

"How connected is the story?" This category is closely linked with complexity but holds its own distinctions. The VRVR typology recognises two mutually exclusive categories within this characteristic: low vs high. A low level of integration has little interconnectedness within the scenarios and partially inform the exercises for the focal groups (e.g. organisations, departments, or stakeholders) (Biggs et al., 2007). Competing lines of development are contained within separate boundaries. The "Global Warming of $1.5^{\circ} \mathrm{C}$ " (de Coninck et al., 2018) scenario project used an overarching focal point - increasing global temperatures - and created 
recommendations for various global responses. The details of their global responses included a variety of adaptation and transformational actions that translated differently, depending on the stakeholder (e.g. countries, regions, cities, communities or businesses). Highly integrated scenarios, however, express the overlapping perspectives, uncertainties, and developments that may unfold between the separate focal groups (Biggs et al., 2007; van Notten et al., 2003). For example, the "VERA-Forward Visions on the European Research Area" (VERA; Teufel et al., 2013, p. 5) scenarios were specifically designed to "help stakeholders with a diverse range of backgrounds and perspectives to arrive at a joint understanding of key challenges and define settings for addressing them." VERA included four scenarios which linked different sectors across the EU on the governance of research, technology, development and innovation (RTDI), for the next 17 years. As a result, the scenarios, though extensive as a collective, were only able to "display central ideas about the futures of RTDI" (ibid.) in order to be communicable and timely for all stakeholders.

\subsubsection{Theme}

"What future images emerge?" Dator (2009) offers four archetypal future images that encapsulates the possible selections of scenarios. Many others have also produced their own selections of archetypes, or generic scenario themes, including Inayatullah's (2008) six pillars, Boschetti et al. (2016) six meta-archetypes, the Global Scenario Group's three archetypes (Gallopín and Raskin, 2002), and Hunt's et al. (2012) convergent of four archetypes for stakehold engagements. These are meant to be generic images of the future, where qualities are not necessarily good or bad, but rather summarise the common content of each archetype, which distinguishes one from the others. Scenario archetypes primarily reduce to Dator's original four - growth, collapse, disciplined, transformational - plus wild card. Dator recognises that scenarios have the potentials to overlap across archetypes, but that most will naturally fall within one.

Growth scenarios project an image of the future which builds on the idea of a growing economy, society, technological advances, etc. Past and present states serve as sources for the trend which informs the particular behaviour of projected "growth". Collapse scenarios envision a future where growth is unsustainable, and eventually leads to some form of integral collapse of one or several systems. These may be economic, resource, moral, cultural, technological collapses, or any number of other areas of our shared environments, which lead to a lower stage of development than is presently experienced. Collapse scenarios can represent a beneficial trend for some (such as the collapse of a repressive oligarchy) or such themes as Gallopín and Raskin's (2002) barbarization, where conventional strategies eventually prove inadequate for addressing external stresses, ultimately fail, and result in either breakdowns of systems or fortress worlds where privilege and stability are secured through authoritarian measures. When present trends prove unsustainable, such as with collapse scenarios, structural uncertainty can help explore conditions of structural change, such as trend-breaks (Dreborg, 2002). Dator (2009) notes that in his experience, most futurists don't want to consider collapse storylines of the future, and often avoid them, even though he - and many others - believe they should. Discipline scenarios are those that see sustained growth of present trends as an unviable option in the future and refocus on survival of the system(s). They highlight fundamental values (e.g. natural, spiritual, religious, political, or cultural) and become disciplined around them. Inayatullah's (2008) back-to-the-future pillar falls within the Discipline category. Transformational scenarios anticipate and welcome fundamental changes, even paradigmatic changes, to the system. Dator focusses heavily on technological changes, but these changes can reach well beyond this single sector. The final archetypal scenarios are wild cards. These are images of the future which go beyond the known knowns (predetermined) and known unknowns (critical uncertainties), and attempt to grapple with the true nature of disruptions by reaching towards the unknown unknowns and introduce novelties. Variations of these themes can be found in the 2050 global scenarios developed for the The Millennium Project. For example, the "Global Normative 2050 Scenario" features extraterrestrial encounters and includes the passage, "In 2040, when the Mars Pioneers won the first Olympic competition in solar sailing between earth and lunar orbits, humanity seemed to pass some threshold of consciousness" (Glenn, 1998).

\subsubsection{Dynamics}

"How extreme is the scenario?" The DL typology was the first to introduce this characteristic and divides it between two the extreme categories trend and peripheral, with an acknowledgement that these lie on a spectrum, where a blending of the two is possible. The CSI typology acknowledges this blended category as compound scenarios.

Trend and peripheral scenarios get their categorical name from the DL typology. Fig. 1 illustrates the path of both trend and peripheral scenarios through the expanding and contracting conical space. Trend scenarios take a 
central path through the cone (i.e. the white space). They can use probabilities to help define the paths of logical connectivity between factors, and present surprise-free storylines, or rely heavily on normative factors with more qualitative data methods (Ducot and Lubben, 1980; Shearer, 2005; van Notten et al., 2003). Probabilities can be determined using a number of methods and models, including subjective measures, trend analysis, and extrapolation of historical data, to name a few. These scenarios can present outcomes from business-as-usual thinking, and by extension, include normative values (Burt, 2007). Peripheral scenarios lie towards the edges of the cones (i.e. the darker space) and represent extreme futures, encompassing disruptions, surprises, or difficult possibilities (Ducot and Lubben, 1980). Peripheral scenarios are as likely to depict utopian storylines as they are dystopian. The VRVR typology share these same titles, expressing similar definitions of trajectories. Compound scenarios present both categories, through a process of blending multiple scenarios together - possibly simpler ones of lower complexity - creating a richer storyline. The CIA method differs from the other scenario schools of practice by integrating a compounding element in the latter stages of the process. Probabilities of future trends and impact projections are coupled, in that the occurrence of one event is influenced (dependent) by the probability or impact of another identified event (Huss and Honton, 1987). Another way is to determine the probabilities of one trend, coupled with the conditional probabilities of subsequent trends (Gordon, 1994a). This can be achieved by dividing the timeline into smaller periods and calculating the estimated cumulative probabilities for each event's occurrence (e.g. using Monte Carlo simulations with stop-gaps between time periods for (re)assessment), or dividing the events along a matrix to map their conditional probabilities.

\subsubsection{Validation}

"What criteria do the scenarios meet?" The evolution of SP has shown that some form of internal validation efforts can help practitioners determine the level of comprehensiveness each scenario can relay to the intended audience. Validation can also be used to reduce a large number of raw scenarios down to a more manageable few. Several experts have offered their suggestions on the minimum criteria for validation (Bradfield et al., 2005; Burt, 2007; Cairns and Wright, 2018; Chermack, 2011; Chermack et al., 2001; Durance and Godet, 2010; Schoemaker, 1993; van der Heijden, 1998; van der Heijden et al., 2002; Wilson, 1998). Some are more widely agreed up on than others. The scenario-level criteria considered necessary by the majority of the literature are plausibility, internal consistency, relevance, transparency, and novelty. In the case of model-level validation, bootstrapping, goodness of fit, intuition, and novel insight are some of the most common validation criteria in the literature. As with other characteristics, these categories can be addressed individually, or in combination.

Plausibility is arguably the most important criterium discussed in the literature, and is described as a series of events capable of happening within the set of known laws (natural/universal/physical). Wright and Cairns (2011) consider plausibility an essential component of the IL method. Cairns and Wright warn, though, that relying on scenarios to remain only plausible can (1) limit the scope of exploratory thinking and/or (2) serve as a feedback loop for existing mental models. This is because plausibility relies primarily on the subjective capabilities and knowledge of the practitioners, and is often conflated with highly probable trends (Ramirez and Selin, 2014). Therefore it is important to cast a wide net with plausibility and consider both 'normal' and crazy (Schultz, 2015), trend and peripheral (Ducot and Lubben, 1980), as possessing the potential for plausibility. Internal consistency is related to coherence, and is defined by Kosow and Gaßner (2008, p. 39) as, "paths to the futures and images within a scenario must be consistent with one another, i.e. their aspects may not be mutually contradictory or even go so far as to exclude each other for reasons of logic and plausibility." Meeting the relevance criterion means the scenario has relatable messages and insights to the future of the intended audience or organisation. An example of this is found in the FEMA (2018) emergency planning scenarios which focus on bringing together different sectors, and therefore must have relevant insights for all sectors in order to work successfully. Wollenberg, et al. (2000) caution that a potential danger of relying too heavily on consistency with outcomes may risk excluding some truly novel scenarios simply because their combinations do not carry the intuitively normative expectations. Transparency is not discussed as much, but an implicit part of all SP literature. Durance and Godet (2010) consider this criterion indispensable for both usefulness and credibility. Transparency allows practitioners to understand the logical underpinnings of the inter-relationships of causal events and outcomes, or what Bunn and Salo (1993, p. 300) coin a "defensible audit trail". This understanding lends credibility to the scenarios. Credibility leads to believability of such potential and plausible futures. Without transparency, scenarios are little more than opaque fiction. Novelty is the final sub-category that is discussed in arguably all SP literature, whether explicitly or otherwise. The purpose of a SP intervention, as stated throughout this paper, is to challenge mental models and introduce changes. Therefore, testing for novelty is a ubiquitous validation to any type of scenario. 
Validation of a model will depend largely on the chosen model and the target variables. For purely extrapolative modelling (to produce a chain of projections), bootstrapping is performed. Confidence intervals are calculated, which widen as the forecast horizon increases, to account for uncertainty in the model. In many cases, the boundaries of a model are estimated by a sample of real-world data. The model is then adjusted and repeatedly compared against the data until an accepted range of variance is reached (determined either by the logic of the model or the desires of the practitioners), and considered a good fit for the system. One way of validating fitness is to perform out-of-sample validation, where different sections of the sample data are withheld with each run of the model, to determine errors. Once satisfied, future parameters are given, and the output is considered valid within a margin of error (Johnson and Sieber, 2011). In the GM case study, the model output aligned with the intuitions of the practitioners (Eppen et al., 1989). This increased the confidence of the product planning analysts, and in turn determined GM's next steps to further test with different analyses before any implementation took place. However, the authors state that, generally speaking, "a good model can, and often does, produce insights not directly related to the original question" (p. 527). The fact that they chose intuition alignment over surprise insights as an indicator of validation may reveal a bias within the practitioners. A good facilitator can help make such biases explicit to the team. Johnson and Sieber's (2011) systems model was validated by generating novel insights about a complex system (i.e. Mongolian Plateau) that had otherwise been absent from the participatory scenario sessions, while also revealing significant knowledge gaps in the participants. Novel insights, as a function of transformative thinking, in the practitioners is one form of validation in Iwaniec's et al. (2014) sustainability vision modelling. Transformative thinking is by and large one of the most agreed upon desired effects from an intervention, and discussed at length in the extant literature. Any one or combination of criteria can be used, including single or multiple scales for validation (Biggs et al., 2007). There is a near infinite number of other criteria that can validate scenarios, and as many tools to analyse each dimension, which should not be shied away from (Bishop et al., 2007). Further validations will largely depend on the chosen method, aims, and dimensions within the scenarios. The presented two categories encapsulate the main sub-categories applicable across virtually all SP interventions. Of course, any discussion on validation should give a nod to Schultz's $(2015$, p. 7) sentiment that the "most important future is the future the greatest number of people believe the most."

\subsubsection{Variable mixture}

"How different are the variables from one another?" The VRVR typology combines both mixture and quantity of variables within one dimension. Though there is a close relationship between these two dimensions, we believe they are distinct enough to serve as separate characteristics. The CSI typology categorises variable mixtures as intradisciplinary or interdisciplinary. Scenarios with intradisciplinary variables focus on a limited perspective that looks to answer a hyper-defined set of questions or goal. These scenarios may have short-term horizons and borrow more heavily from normative values. An example of intradisciplinary scenarios can be found from the EHRAG group (Audit Scotland, 2019). Each workshop comprised of a group of experts and community members who had a special interest in a particular policy, as it applied to a specific population. The motivation would be to explore the policy impact on the designated population, within a small region of Scotland, spanning no farther than the next review period (6 or 12 months). These workshops would produce focused scenarios. Though limited in scope, some scenarios would be highly elaborative, while others would comprise no more than a paragraph. Interdisciplinary scenarios sample knowledge from different, possibly opposing perspectives, and could include clusters that blend factors from several topics, such as when STIRDEEPER, PESTEL, or STEEP methods are used to facilitate shared creative thinking (Wright et al., 2009). The VRVR typology labels these categories homogeneous and heterogeneous mixes, respectively.

\subsubsection{Variable types}

"What are the variables?" The variables are arguably the "meat" of the scenarios. Variables are the driving forces, factors, dimensions and events that make up the scenarios, and therefore deserve a place in any attempt at fully developing a typology of SP interventions. Variables are primarily critical uncertainties or predetermined. Critical uncertainties are those driving forces that exist in the present and potential future organisation's environment, but do not have a predictable path of development (Kahn and Weiner, 1967; van der Heijden et al., 2002). The "Global Europe 2050" report (Commission, 2011) begins a structured approach with the identification of critical uncertainties that were grouped into six main dimensions: global demographic and societal challenges, energy and natural resources, economy and technology prospects, geopolitics and governance, territorial and mobility dynamics, and research, innovation, and education. van de Riet et al. (2008) example the development of energy prices, $\mathrm{CO}_{2}$ emission policies, entrance of low-cost carriers in the market, and changes in point-to-point networks as critical uncertainties for the Amsterdam Airport Schiphol transport 
infrastructure planning sessions. Predetermined variables, are those driving forces and trends that will have an impact, but will eventually resolve themselves in time. These are "already in the pipeline" and offer a certain level of predictability (van der Heijden, Bradfield et al., 2002, p. 269). For example, the US deficit will exist for decades, most likely generations, to come. How the US deficit will impact a specific organisation and how the organisation will deal with the impacts in the future is uncertain, but the deficit itself is a predetermined. A general word of warning from the extant literature, though, is to caution against assuming too many variables are predetermined. As Simpson (1992, p. 15) prophetically states, "What is first perceived to be predetermined often turns out to be a critical uncertainty." It is worth noting that all SP interventions must deal with unspecified uncertainties that are inherent in the system (Dreborg, 2002). Also referred to as hard (Dror, 1988) or genuine (Eriksson, 2004) uncertainties, these are the true unknowables, the variables and behaviours that are not possible to anticipate or predict (van der Heijden, 1998). It is by way of these inherent blinders that the possibility of surprise can arise (Dreborg, 2002). More often than not, the intervention process will lead to identifying a hybrid of variables from all the categories, and rightly so.

\subsubsection{Deviation}

"How different are the scenarios from each other?" The title and categorical names borrow from the VRVR typology, but the underlying assumption of the characteristic is best expressed by Heugens and van Oosterhout (2001, p. 863) when they state, "The scenario method never relies on a single storyline." This is also echoed in Premise 4 of Cairns and Wright's (2018a) scenario model.5 A group of scenarios' deviation is measured in the range of plausible futures that are taken into account (van Notten et al., 2003). Two categorical differences lie within this characteristic and can be interpreted on a spectrum between low deviation (conventional) and high deviation (alternative). The VRVR typology describes conventional scenarios as those that present business-asusual thinking, and adhering to the status quo, by retreading the past to define the future. Conventional scenarios help to fine-tune existing or proposed strategies, which can cause a fair amount of overlap between them. For example, when motivations aim to build preserving scenarios, such as finding the most efficient plausible paths for city evacuations in the face of disaster preparedness, the resulting scenarios discuss a number of the same factors due to the shared predetermined variables (heavy traffic) and resources (roads and highways). Alternative scenarios, on the other hand, present significantly different content and/or trajectories from each other, and may have few to no aligning factors between them. They are often used to challenge conventional thinking and assumptions, and to raise awareness of potential surprises (van Notten et al., 2003). Though the DL typology considers these contrasting scenarios as a sub-category of peripheral scenarios, this is not necessarily the case, and more importantly, the topic touches upon a different characteristic altogether, and therefore is categorised as a level of deviation. Between the two extremes are any number of deviation mixtures. Cairns (2014) offers an example of compound and dynamic deviations at play. The author presents a case study using a Critical Scenario Method to analyse end-of-life ship disposal, resulting in four plausible scenarios. From the workshops, at least two scenarios are developed free of surprises or disruptions - Scenario A: Global Cooperation and Scenario D: Business as Usual - and one scenario that includes at least one disrupted path Scenario C: Bangladesh Goes Alone. No single scenario can be considered overall 'optimal' or 'worst-case' since these qualities vary by focal group.

\subsubsection{Quantity}

"How many scenarios?" Throughout the intervention, a selection of scenarios will eventually emerge from the process. The number of scenarios that are fully developed and used to challenge mental models and inform future decisions will depend on a number of factors, including, but not limited to, the chosen method/school, goals of the organisation, purpose of the intervention, and availability of resources (time, practitioners, technology). Amer et al. (2013) admit that there is no precise answer to the question of how many scenarios is optimal. However, the more scenarios, hypotheses, and dimensions that are developed, the more the information will lead to an overwhelming number of possible combinations, and potentially to decision fatigue, default choices, or worse, decision deferral - where no decisions are made at all.

There is a general consensus that more than one scenario should be developed. A single scenario offers highly limited parameters and no comparisons to other future realities with which to challenge mental models and alternative options. Which leads to a minimum recommendation of two scenarios. The dual creation could lead to good-vs-bad dichotomies (Schnaars, 1987), or best-guess vs deadliest-enemy (Mitroff and Emshoff, 1979), or high vs low parameters (Avnery et al., 2011). In the case of Avnery et al., the two scenarios isolated from the 
IPCC Report on Emissions Scenarios represent the upper- and lower-boundary projections for surface ozone emissions by 2030. By focusing on just the two most extreme scenarios, the authors are able to eliminate a lot of information-rich noise from their report and focus attentions on the boundaries of plausible future developments/degradations of crops. A traditional method is to develop three scenarios. Often two are some version of best-and worst-case scenarios, with a third presenting a business-as-usual, trend extrapolation (Schwab et al., 2003), middle ground (Wilson, 1978), or most-likely (Bezold, 2010; de Kluyver, 1980). Other times, three scenarios can engender no specific best/worst/other distinction, but rather develop wholly different storylines built around different key driving forces, to reveal equally plausible, successful, but unrelated futures. This is the case with Erdmann and Hilty's (2010) scenario study of the potential impacts the information and communication technology can have to reduce greenhouse gasses. Three scenarios were developed that each reflect growth, moderation, and decline in various sectors of the different futures. Practitioners of the IL school often develop four scenarios. The two most impactful and uncertain clusters of causally related driving forces are each elaborated on, and built into their own opposite or differing "limits of possibility" (van der Heijden, 1998, p. 209). The two new opposite storylines for each of the two clusters are cross-compared in a $2 \times 2$ matrix to create four distinct scenarios. Ramírez and Wilkinson (2014) review the $3 \times 3$ matrix method which offers a volume of possibilities, from which a number of scenarios can be fleshed out. Bunn and Salo (1993) suggest that when testing for robustness and flexibility of a strategic plan or policy, several scenarios may be needed before a satisfactory analysis can be achieved. Amer et al. (2013) offer a great comparison of suggested scenario quantities in the literature, spanning all the major schools of practice. The authors show that the range of suggested scenarios that could lead to a successful SP intervention largely fall between two and six, with van der Heijden (1998) and Schoemaker (1993) leaving the door open for any quantity and variety greater than two.

\subsection{Section 4: Scenario impact}

The final section of the CSI typology focuses on the processes carried out as a result of the intervention, and aims to answer the question, "How impactful was the intervention?" This section comes from early awareness by Wack (1985b, p. 139) that "the interface of scenarios and decision makers is ignored or neglected." The work that emerges from SP interventions should not stop when the workshops end, or when the reports are drafted. A necessary factor in SP is the level of impact interventions can carry with them, post workshop. Potential impact factors are discussed at length in scenario literature, after all what is the purpose of SP if not the potentiality for change? As Godet and Roubelat (1996, pp. 165-166) recommend, "the container matters little so long as one is intoxicated by the content-communication." Only the VAV typology includes features of this section, along with discussions in a number of review papers. Bishop et al. (2007) include this final stage (acting) in their generic approach. This is when plans are implemented, results are communicated, agendas developed, and when applicable, strategic thinking is institutionalised. With the addition of this fourth section, the CSI typology attempts to redefine traditional perspectives by extending the "full intervention" concept from just the planning, scoping, and developmental stages to include the follow-through.

\subsubsection{Decision makers}

"Who is responsible?" Scenarios are developed for an audience (Amer et al., 2013). That audience will be responsible for initiating what Cairns, et al. (2017) refer to as articulated action, and may include the board of directors, advisors, members of government agencies, industry, NGOs, private organisations, and general audiences (Barber, 2009). There are three potential groups who could hold this responsibility. The practitioners from within the SP process, organisational members outwith the process, or a collaboration of representatives from both groups.

Ideally, the decision makers should be the same as those chosen in the practitioners dimension, within the previous stages of SP intervention. Many insist this is a necessary element to the success of the intervention and is particularly true in the IL school (Cairns and Wright, 2018; Masini and Vasquez, 2000; van der Heijden, 1998; van der Heijden et al., 2002; Wack, 1985a). A core assumption to the SP methodology (and by extension, scenario thinking) is that through the multi-step practice of thinking about and framing the future, a practitioner's mental models are made explicit, challenged, and then changed (Cairns and Wright, 2018; Dufva and Ahlqvist, 2015; Mackay and McKiernan, 2018). It is from this change that better knowledge of the future develops. Therefore, the cognitive effects from participating in a SP intervention are as important as the scenarios themselves with regard to level of impact the intervention will have on the organisation. From Klein and Linneman's (1981) case histories, the authors discovered that the less managers (i.e. problem owners) were involved with the scenario intervention, the less they understood the use of the interventions, and possibly the existing inadequacies of conventional forecasting techniques. Ascher's (1978) review shows that the most 
common reason for errors in forecasting were due to poor underlying assumptions. Assumptions that could have been challenged by participating in a full SP intervention. However, any number of interventions are attended almost entirely by practitioners and facilitators who carry little-to-no decision-making power, who then must shoulder the responsibility of reporting and interpreting the resulting scenarios to - often higher ranked decision makers outwith the workshop (e.g. supervisors, CEOs, upper management, etc.). There are many reasons the decision makers do not/cannot attend a SP workshop: time-poor executives, geographical restraints, and changes in the process midstream, for example. These arrangements can bring later difficulties, given that the mental models of the decision makers and those of the practitioners will not be as well aligned. As van der Heijden (1998) discussed, SP can only lead to institutional learning when there is alignment of ideas amongst the ranks, and this is best achieved through full participation. A compromise to the two extreme options is a collaboration of representatives from both groups. This is the case when the decision makers can only participate in part of the intervention, as with the British Airways case study which took most of a year to carry out multiple interviews and workshops, attended by different practitioners (Moyer, 1996).

\subsubsection{Organisational capacity}

"How much does the organisation absorb?" SP is only as valuable as the level of adoption the organisation is willing to achieve, of the new knowledge and insights. "Even well-constructed, thoroughly analysed scenarios can be of little use and relevance, if the organisational capacity to absorb them is poor" (Volkery and Riberio, 2009, p. 1199). Organisations have the capacity for engagement, abandonment, or selective adoption of the knowledge, outcomes, and policies discovered during SP.

Fully engaged organisations are those that actively integrate the information into their business models, culture, politics and planning. Those with active scenario narratives embed SP in a "formal process of strategy development by making it the basis of the corporate planning cycle" (van der Heijden, 1998, p. 242). Full engagement of scenario learning is also facilitated by a system of safety nets, where organisations can afford potential set-backs or disruptions in the process. Examples of such safety nets can be found in GM's capacity planning strategies proposed from their scenario learning (Eppen et al., 1989). GM foresaw high-risk closures that would cost millions of dollars and involve thousands of people. Though the details of their exact strategy are not shared, they did discuss taking additional measures to implement pieces of capacity strategies, in incremental steps, to allow for unforeseen failures without damaging GM shares too extensively, and allow for recovery efforts.

It is often the case, however, that SP interventions are commissioned, executed, with full reports delivered to the decision makers, but never progress beyond, and the knowledge is abandoned. This can be due to a number of reasons. One common reason is the unforeseen disruptions during the course of a SP intervention, which can change the dynamics of the organisation in a way that invalidates many of the assumptions the scenarios were based on, therefore preventing the organisation from adopting the learning and, in essence, abandoning the knowledge. Cairns et al (2017) experienced low capacity for adoption in their Tasmania Case due to barriers created by political arrangements and power relations. Another way in which SP knowledge can be adopted by the organisation is selectively. This may be the more common method of adoption, as well. In particular, when the intervention includes a heterogeneous group of practitioners from different sectors - as in the European Commission scenario projects - it could be the case that level of power, responsibility, and influence varies between the sectors as a function of their interrelationship, therefore creating an inequality in their abilities to adopt change.

\subsubsection{Uncertainty strategy}

"What quality of uncertainties inform strategy?" Uncertainties are closely linked to the variables and causal relationships identified from the process and content. The types of uncertainties inherent in the scenarios will inform the strategy or next steps for the organisation. The three main qualities of variable uncertainty are discussed at length throughout Strangert's $(1974,1977)$ work: dynamic, static, or quasi-static.

Dynamic uncertainties are expected to resolve with time. This brings a level of anticipated knowability to the scenario. The VAV typology offers several potential strategies for dynamic uncertainty. The adaptive strategy is a step-wise process, where such techniques as trial-and-error, can help build successive knowledge and allow efforts to adapt to new conditions. Adaptive strategies include efforts to systematically shape uncertainties (Dreborg, 2002; van de Riet et al., 2008). Recognising the quality of uncertainty revealed through the SP intervention, an organisation may choose to influence uncertainties by taking steps to directly engage with key 
actors to increase knowledge that will reduce specific uncertainties. Investigating uncertainties that emerged from the scenarios is another way to reduce knowledge gaps, while spreading the risk allows an organisation to divide the risks associated with uncertainties amongst the regions that are best equipped to work with them. Static uncertainties do not lend themselves to being easily altered or diminished (i.e. predetermined). The VAV typology includes a fixed strategy, where a single path is chosen and administered. Fixed strategies are part of the business-as-usual profile. If, however, the organisation's motivations involved a bi-directional process that resulted in attempts to capture the full range of alternatives in order to help ensure that decisions resulted in the best outcomes across a range of events, then Dreborg's (2002) strategy of flexibility or the VAV typology's hedging strategies may be the best choice. A strategy of flexibility requires the organisation to pick a single strategy (i.e. one-shot decision) that works best for all known plausible outcomes (Eriksson, 2004). Hedging strategies allow organisations to insure themselves against the uncertain outcomes, create an exit plan in the case of disruptions, and/or diversifying their risk response. Quasi-static uncertainty is much like static, in that this uncertainty appears to be unalterable. However, it can be better understood through limited exploration. Using time as a tool, practitioners and organisations can delay their decisions to a negligible degree while they gather more information to resolve some of the uncertainty (Eriksson, 2004). Eriksson stresses that each uncertainty is situation-dependent, and the chosen strategies will be dependent as much on the quality of the uncertainty as it will be on the goals of the intervention and content of the scenarios. The VAV typology suggests signposting for these types of uncertainties. After identifying any quasi-static uncertainties, an organisation can determine the threshold, or trigger value, where policy makers and management reassess their plan and adjust for change.

\subsubsection{Implementation}

"How will the organisation proceed?" One of the most important elements of SP is its effect on the organisation's abilities to successfully navigate the unknown future. This CSI typological characteristic is directly dependent on organisational capacity. An important note about the implementation efforts from any SP intervention stems from our understanding of uncertainty. Burt and van der Heijden (2003, p. 1020) identify that the continued and constant presence of uncertainty shifts the efficacy of an intervention from the traditional episodic format, to an "ongoing way of thinking" where the organisation looks for a best strategy process.

Organisations can proceed as they began, with business-as-usual policies, or by adopting transformational policies and practices. The decision makers are the primary individuals responsible for initiating these manoeuvers. Business-as-usual procedures, post-intervention, are a major issue with the field of SP. This could be due to the organisation not applying the learning gained from their SP intervention, or worse, the intervention did not effectively challenge the mental models of the practitioners. Any number of reasons could lead to what Wright et al. (2008) consider strategic inertia. These could include lack of engagement with scenario development by the decision makers, roles and purposes for action are unclear, procrastination, unstable institutional settings and organisational capacity, and/or a strong risk-averse attitude that stifles change (Graetz, Rimmer, Lawrence, and Smith, 2002; Lindgren and Bandhold, 2003; Parson et al., 2007; Volkery and Riberio, 2009). The Tasmania Case illustrates this level of implementation, and is presented in Appendix $B$ with a discussion of its SP profile. Other reasons include lack of trust in the experts and facilitators engaged in the scenario constructions (Volkery and Riberio, 2009). With that said, there is always the rare chance that practitioners successfully participated in a SP workshop, developed multiple scenarios of plausibly different futures, and determined that the policies in place are, in fact, the best methods with which to continue. This is the kind of outcome that could develop from non-Cartesian approaches where the purpose of the intervention is to map normative policies against what-if scenarios to determine the viability of their successes.

Transformational changes represent a form of organizational ambidexterity (Bodwell and Chermack, 2010). These changes can proceed through structured, semi-structured, or unstructured methods. Organisations that adopt transformational changes, at any level, highlight the second domain, "Learning Theory", of Chermack's (2011) Six Domains of SP Theory. Structured transformational changes indicate a well-developed plan that accounts for bottom-up/top-down influences, process checkpoints, and a deep understanding of the organisation's integrated efforts, that can lead to fundamental shifts in organizational strategy (March, 1991). According to Gersick (1991) the purpose of SP is to introduce changes in a structured manner (i.e. methodically). Semi-structured implementation is the trial-and-error method of change. As Mintzberg (1994, p. 111) states, "We think in order to act, to be sure, but we also act in order to think." By trying out plans, much like experimentalists, management can begin to recognise what works, what doesn't, and begin to build strategies from the incremental knowledge. Implementing small changes in non-trivial ways can afford an organisation the opportunity to realise the impact of their transformations without engaging in the potentially 
high-risk efforts of more ubiquitous changes. One method is illustrated by Derbyshire and Wright's (2014) application of Taleb's (2012) antifragile methodology. The authors show how small-scale experimentation of scenario insights creates an incremental approach to decision-making, and in turn, "provides decision-making options at each incremental point" (p. 222), thereby allowing the organisation to continue or discontinue based on the results. In the GM case study, the most useful suggestions from the scenario workshops were to close several plants and eliminate certain products. To implement such an effort, a step-wise, incremental approach was adopted with further analyses to help determine each step to be taken and when, along with stop-gaps for incremental evaluations (Eppen et al., 1989). Unstructured methods are also referred to as ad hoc methods of implementation. Taking on an unstructured approach can be reflective of adverse contingent circumstances, poor communication between the players, or unpredictable and uncontrollable exogenous changes (Ströh, 2004; Volkery and Riberio, 2009).

\section{Discussion}

To review, the aims of this paper are to (1) present a comprehensive typology for SP interventions that offers practitioners clear profiles for guidance towards fundamental changes in perceptions and organisational actions, (2) aid scholars in empirically exploring the necessary dimensions of SP interventions, and (3) join in the effort of building a stronger foundation for the field of SP - and by extension, futures and forecasting methods at large. The result is a four-themed typology with semi-reducible dimensions, built from the knowledge developed through the major schools of practice, empirical and conceptual work, case studies, and real-world applications, from across the globe, for the better part of a century. The CSI typology frames SP interventions through antecedent preparation, a process of development and content, with outcomes for organisation-level impact, which sets it apart from the traditional SP technique studies, and guides the facilitator along a more logical process, which should, in turn, improve both the utility and comprehension of SP, and increase its value to an organisation. Bringing it all together, "the collective influence of dialogue, conversation quality and engagement, learning, decision making, mental models, and leadership on organization performance and change... combine to create performance-based scenario planning" (Chermack, 2011, p. 54), which is the final domain of the Chermack's SP theory.

As stated in the limitations section, some of the dimensions of previous typologies do not fit into the discrete dimensions of the CSI typology. Instead they describe a selection of dimensions that comprise a SP profile. This is the case with the WE typology's three themes: problem-focused, actor-centric, and RIMA. Problem-focused scenarios address systems of low uncertainties and issues with low stakes, where the knowable future environment provides objective, quantifiable factors, and scenarios develop free from value judgments - norms. These scenarios focus on the outcomes more than the process. Actor-centric scenarios source qualitative, subjective information through strategic conversations that lead to group consensus on any number of variables. These methods are more concerned with the depth of the conversations, changes in cultural perspectives, and practitioner learning than with the outcomes. These scenarios produce cross-discipline variables presented along a temporal chain storyline. RIMA scenarios blend quantitative methods of probability analyses with qualitative methods of group-based discussions. They include predetermined uncertainties - environmental variables free of preferential treatments - along with high levels of uncertainties, where exploratory efforts reveal a plethora of options, not necessarily agreed upon by all practitioners. Appendix C plots a SP profile against the WE typology's three themes.

\subsection{Descriptive, explanatory, and predictive}

A repeated issue amongst the extant literature is the lack of strong empirical evidence to support the general claims that SP effectively changes mental models, and these changes bring a higher probability that the organisation will be more successful. A number of studies have attempted to fill this knowledge gap (see Bradfield, 2008; Chermack and Nimon, 2008; Haeffner et al., 2012; Kuhn and Sniezek, 1996; Meissner and Wulf, 2013; Phadnis et al., 2015; Phelps et al., 2001; Schoemaker, 1993). Though their results are thought provoking, collectively their data are still not enough. Part of the reason is the sometimes stark differences in methodological approaches to the studies. Rather than leave this issue unresolved, the CSI typology hopes to serve as a framework (i.e. descriptive function) for empirical research. Reinventing the methodological wheel for every SP intervention study is not necessary when a unifying theory is provided, with tools (i.e. typologies) for measuring against real-world and lab-based phenomena.

By presenting dimensions that are dependent, independent, interrelated, and mutually exclusive, the CSI typology can guide hypothesis development and increase a study's explanatory abilities. For example, Phadnis et 
al. (2015) investigate the effects of SP on confidence and long-range judgments. Their results reveal a bias in confidence by participants for preferred plans and a change in preference for flexible long-range investment solutions. Schoemaker's (1993) study, however, reveals that scenario development does not affect confidence as much as scenario content. Kuhn and Sniezek (1996), on the other hand, reveal that confidence adjusts as a function of scenario time horizon, direction, and number of scenarios. These seemingly conflicting results could potentially be more clearly explained with a better understanding of their SP profiles. One method would be to determine the featured organisation's epistemological position (Phadnis et al. work with in- house experts) to more predictably plot the progress of the experimental intervention to their logically expected conclusions. For example, an organisation that takes a Cartesian approach to a SP intervention will not be motivated in the same way toward implementing active, transformational changes compared to a non-Cartesian approach, and this, in return, can hypothetically engender different motivations within a study's participants (proxy-practitioners). The same can be used for understanding each study's time horizon. Phadnis et al. use scenarios with a long-term horizon (30 years), Kuhn and Sniezek use a long-term horizon divided in to medium-term sections (50 years divided into decades), and Schoemaker's study uses short-term horizons (1-5 years). The particular temporal dimensions will have a direct effect on the level and quality of uncertainty in the developed scenarios, which will determine the type of uncertainty strategy. As well, sourcing the sample of participants from a closely selected population (e.g. MBA students with Schoemaker and inhouse experts with Phadnis et al.) may generate a homogeneous group (depending on demographic criteria), therefore eliminating the heterogeneous profile.

For facilitators and practitioners, the CSI typology offers a predictive functionality to their SP intervention efforts. In line with the empirical discussion, understanding an organisation's epistemological approach and motivations will determine the types of impact the intervention could lead towards. The exclusion of decision makers in the group of practitioners may have a higher probability of leading to an abandonment of the scenario lessons, resulting in an business-as-usual implementation and reinforcement of norms. If the goal of the intervention is to create chain scenarios that present a continuous storyline, then the facilitator(s) can ensure that a congruent time horizon is made explicit to the practitioners during the antecedent preparation stage, which will inform their variable scale, data type and collection.

It is sometimes the case that conditions change during the execution of a SP intervention, whether it be a loss/change in some practitioners or a change in available institutional resources or conditions. Any changes in the process have the potential to alter the course of the intervention. By having developed a CSI typological profile, facilitators can better anticipate the outcomes of these last-minute changes, and make real-time alterations in the intervening SP process to counter any biasing from the disruptions and decrease the chances of failure in efficacy.

Another aim of CSI is to help organisations that have limited resources. SP interventions are already resource intensive, so organisations with limited resources are the least likely to utilize the benefits of an intervention (Phelps et al., 2001). The CSI typology can help facilitators develop a process that maximises available resources through carefully considered techniques based on the particulars of the SP profile.

\subsection{Best-practice suggestions}

Though the SP methods are pragmatic, with any number of dimensions proving necessary/unnecessary for a given SP intervention, there are a few best-practice suggestions provided by the field. First, it is important to reiterate Ducot and Lubben's (1980) suggestion regarding the use of typologies. Aligning scenarios with the cross-selection of the typology's dimensions, creating a unique SP profile, will result in scenarios that are more resilient to methodological criticisms, and by extension, more credible. An example is given of a scenario planning profile in Appendix B using the Tasmania Case. Creating their profile, retroactively, allows us to quickly identify potential points of friction which may have led to the low efficacy of the intervention, as well as points of cohesion and their benefits.

It is a standard task in all SP schools to initially identify a problem, goal, or issue at the start (Bradfield et al., 2005). An effective SP intervention requires extensive planning and preparation. This initial point is illustrated well in the follow-up analyses from Moyer's (1996) "British Airways" case study. The author recognised that the SP team "underestimated the amount of work involved in developing plausible but challenging scenario stories... the team would have benefited from having a full-time analyst working on the problem... more contact by the team with external experts would have been useful... facilitators were doubling as presenters and vice versa," and many of the commitment issues with their team "could have been overcome if the presenters had been included more in the planning and running of each workshop" (p. 179). 
Success is greatly increased by ensuring at least one expert facilitator is designated to the task (Bradfield, 2008). For large-scale SP interventions, such as with the FEMA, ESPAS projects, and British Airways case study, multiple facilitators with specific designations within the workshops may be necessary, in order to meet the needs of the tasks. The British Airways case study included five facilitators, each responsible for the workshop phase (Moyer, 1996). Facilitators are able to remain more vigilant than practitioners with respects to regarding unnecessary constraints and reducing them where possible (Duckett, et al., 2017). Even more so, creating a scenario planning profile that includes at least one expert facilitator, and a heterogeneous group with at least one external expert (e.g. remarkable person), will greatly increase the chances of avoiding standard pitfalls that stem from bounded rationality. This is a dimension of the second domain of Chermack's (2011) SP theory, "DecisionMaking Theory", and a key concern with SP. Bounded rationality is the inhibition of idea generation due to an individual's limited knowledge (Simon, 1972). This is an unavoidable feature of being a thinking human being, but measures can be taken in other CSI dimensions to counter such limitations.

A final recommendation for increasing success is ensuring the decision makers comprise at least part of the practitioners. Volkery and Riberio (2009, p. 1201) explain, "The main impacts of scenarios often result more from the process of developing them rather than from any published product describing the scenarios that were created." It is in the process that such importance lies because this is when mental models are made explicit and challenged (Chermack, 2011). The effects of challenging mental models are what increase adoption of the knowledge gained from SP. Further, "it has implications for the extent to which people trust scenarios and thus use them" (Volkery and Riberio, 2009, p. 1202). As one practitioner reported, after participating in a series of SP workshops, "In painting that picture it helped build relationships, it helped build that sense of common purpose and understanding. I think that's very powerful" (Bowman et al., 2013).

\section{Acknowledgements}

We thank the reviewers for their insightful suggestions and help locating key publications. The article was improved, in no small part, by their commitment to a supportive review process. We also thank Chateauneuf-dupape for facilitating the discovery of necessary and pertinent knowledge.

Please cite as: Crawford, M. M. (2019). A comprehensive scenario intervention typology. Technological Forecasting and Social Change, 149, 119748. https://doi.org/10.1016/j.techfore.2019.119748 


\section{References}

1. Ackoff, R. L. (1981). Creating the Corporate Future: Plan or Be Planned For. Wiley.

2. Allington, G. R., Fernandez-Gimenez, M. E., Chen, J., \& Brown, D. G. (2018). Combining participatory scenario planning and systems modeling to identify drivers of future sustainability on the Mongolian Plateau. Ecology and Society, 23(2), 9. doi: 10.5751/ES-10034-230209

3. Amer, M., Daim, T. U., \& Jetter, A. (2013). A review of scenario planning. Futures, 46, 23-40. doi: 10.1016/j.futures.2012.10.003

4. Ascher, W. (1978). Forecasting: An Appraisal For Policy-Makers and Planners. Baltimore: Johns Hopkins University Press. doi: 10.2307/1954899

5. Audit Scotland. (2019). Mainstreaming equality and equality outcomes. Edinburgh: Accounts Commission \& Audit Scotland. Retrieved from: https://www.auditscotland.gov.uk/uploads/docs/report/2019/as_mainstreaming_equality_report_1719.pdf

6. Avnery, S., Mauzerall, D. L., Liu, J., \& Horowitz, L. W. (2011). Global crop yield reductions due to surface ozone exposure: 2. Year 2030 potential crop production losses and economic damage under two scenarios of O3 pollution. Atmospheric Environment, 45(13), 2297-2309. doi: 10.1016/j.atmosenv.2011.01.002

7. Bailey, K. D. (1994). Qpologies and taxonomies: An introduction to classijication techniques. Thousand Oaks, CA: Sage.

8. Balarezo, J., \& Nielsen, B. B. (2017). Scenario planning as organizational intervention: An integrative framework and future research directions. Review of International Business and Strategy, 27(1), 2-52. doi: 10.1108/RIBS-09-2016-0049

9. Barber, M. (2009). Questioning scenarios. Journal of Futures Studies, 13(3), 139-146. Retrieved from https://jfsdigital.org/articles-and-essays/2009-2/vol-13-no-3-february/scenario-symposium/questioningscenarios-2/

10. Bezold, C. (2010). Lessons from using scenarios for strategic foresight. Technological Forecasting and Social Change , 77, 1513-1518. doi: 10.1016/j.techfore.2010.06.012

11. Biggs, R., Raudsepp-Hearne, C., Atkinson-Palombo, C., Bohensky, E., Boyd, E., Cundill, G., .. . Zurek, M. (2007). Linking futures across scales: A dialog on multiscale scenarios. Ecology and Society, 12(1), 17. Retrieved from: http://www.ecologyandsociety.org/vol12/iss1/art17/

12. Bishop, P., Hines, A., \& Collins, T. (2007). The current state of scenario development: An overview of techniques. Foresight, 9(1), 5-25. doi: 10.1108/14636680710727516

13. Börjeson, L., Höjer, M., Drebord, K. H., Ekvall, T., \& Finnveden, G. (2006). Scenario types and techniques: Towards a user's guide. Futures, 38, 723-739. doi: 10.1016/j.futures.2005.12.002

14. Boschetti, F., Price, J., \& Walker, I. (2016). Myths of the future and scenario archetypes. Technological Forecasting and Social Change, 111, 76-85. doi: 10.1016/j.techfore.2016.06.009

15. Bowen, G. (2008). Naturalistic inquiry and the saturation concept: A research note. Qualitative Research, 8(1), 137-152 . doi: 10.1177/1468794107085301

16. Bowman, G., MacKay, R. B., Masrani, S., \& McKiernan, P. (2013). Storytelling and the scenario process: Understanding success and failure. Technological Forecasting \& Social Change, 80, 735-748. doi:10.1016/j.techfore.2012.04.009

17. Bradfield, R. M. (2008). Cognitive barriers in the scenario development process. Advances in Developing Human Resources, 10, 198-215. doi: 10.1177/1523422307313320

18. Bradfield, R., Derbyshireb, J., \& Wright, G. (2016). The critical role of history in scenario thinking: Augmenting causal analysis within the intuitive logics scenario development methodology. Futures, 77, 56-66. doi: 10.1016/j.futures.2016.02.002

19. Bradfield, R., Wright, G., Burt, G., \& van der Heijden, K. (2005). The origins and evolution of scenario techniques in long range business planning. Futures, 37(8), 795-812. doi: 10.1016/j.futures.2005.01.003

20. Brown, B. B. (1968). Delphi Process: A Methodology Used for the Elicitation of Opinions of Experts. Santa Monica, CA: The RAND Corporation. 
21. Bryant, B. P., \& Lempert, R. J. (2010). Thinking inside the box: A participatory, computer assisted approach to scenario discovery. Technological Forecasting and Social Change, 77, 34-49. doi: 10.1016/j. techfore.2009.08.002

22. Bunn, D. W., \& Salo, A. A. (1993). Forecasting with scenarios. European Journal of Operational Research, 68, 291-303. doi: 10.1016/0377-2217(93)90186-Q

23. Burt, G. (2007). Why are we surprised at surprises? Integrating disruption theory and system analysis with the scenario methodology to help identify disruptions and discontinuities. Technological Forecasting \& Social Change, 74, 731-749. doi:10.1016/j.techfore.2006.08.010

24. Burt, G., \& van der Heijden, K. (2003). First steps: Towards purposeful activities in scenario thinking and future studies. Futures, 35, 1011-1026. doi: 10.1016/S0016-3287(03)00065-X

25. Cairns, G. (2014). A critical scenario analysis of end-of-life ship disposal: The "bottom of the pyramid" as opportunity and graveyard. Critical Perspectives on International Business, 10(3), 72-189. doi: 10.1108/cpoib-10-2012-0049

26. Cairns, G., \& Wright, G. (2018). Making scenario interventions matter: Exploring issues of power and rationality. Futures Foresight Science, 1-14. doi: 10.1002/ffo2.10

27. Cairns, G., \& Wright, G. (2018). Scenario Thinking (2nd ed.). Switzerland: Palrave Macmillan.

28. Cairns, G., Wright, G., Fairbrother, P., \& Phillips, R. (2017). 'Branching scenarios' seeking articulated action for regional regeneration - A case study of limited success. 124, 189-202. doi: 10.1016/j.techfore.2017.01.014

29. Chermack, T. J. (2002). The mandate for theory in scenario planning. Futures Research Quarterly, $18(2), 25-28$.

30. Chermack, T. J. (2011). In Scenario Planning in Organizations: How to Create, Use, and Assess Scenarios (1st ed.). Oakland: Berrett-Koehler.

31. Chermack, T. J. (2018). An analysis and categorization of scenario planning scholarship from 19952016. Journal of Futures Studies, 22(4), 45-60. doi:10.6531/JFS.201806.22(4).0004

32. Chermack, T. J., \& Nimon, K. (2008). The effects of scenario planning on participant decision-making style. Human Resource Development Quarterly, 19, 351-372. doi: 10.1002/hrdq.1245

33. Chermack, T. J., Lynham, S. A., \& Ruona, W. E. (2001). A review of scenario planning literature. Futures Research Quarterly, 17, 7-31. doi: 10.1016/j.futures.2012.10.003

34. CNECT, E. C. (2016). Digital futures final report- A journey into 2050 visions and policy challenges. Brussels: European Commission. Retrieved from https://ec.europa.eu/futurium/en/content/digitalfutures-final-report-journey-2050-visions-and-policy-challenges

35. Commission, D.-G. f. (2011). Global europe 2050. Luxembourg: Publications Office of the European Union. doi: $10.2777 / 79992$

36. Cooper, C., \& Block, R. (2006). Disaster: Hurricane Katrina and the failure of Homeland Security. NY: Henry Holt and Co.

37. Craiger, J., Goodman, D., Wiss, R., \& Butler, B. (1996). Modeling organizational behavior with fuzzy cognitive maps. International Journal of Computational Intelligence and Organizations, 1, 120-123. doi: 10.1007/978-3-642-03220-2_1

38. Dator, J. (2009). Alternative futures at the manoe school. Journal of Futures Studies, 14(2), 1-18.

39. Davis, P. K., Bankes, S. C., \& Egner, M. (2007). Enhancing Strategic Planning with Massive Scenario Generation: Theory and Experiments. CA: RAND Corporation.

40. de Coninck, H., Revi, A., Babiker, M., Bertoldi, P., Buckeridge, M., Cartwright, A., ... Sugiyama, T. (2018). Strengthening and implementing the global response. In V. M. Delmotte, P. Zhai, H.-O.

Pörtner, D. Roberts, J. Skea, P. Shukla, ... T. Waterfield (Eds.), Global Warming of $1.5^{\circ}$ C. An IPCC Special Report on the impacts of global warming of $1.5^{\circ} \mathrm{C}$ above pre-industrial levels and related global greenhouse gas emission pathways, in the context of strengthening the global response to the threat of climate change. IPCC. Retrieved from https://www.ipcc.ch/report/sr15/chapter-4strengthening-and-implementing-the-global-response/ 
41. de Kluyver, C. A. (1980). Bottom-up sales forecasting through scenario analysis. Industrial Marketing Management, 9, 167-170. doi: 10.1016/0019-8501(80)90024-3

42. de Vasconcelos, Á., Grevi, G., Peral, L., \& Zanders, J. P. (2012). Global trends 2030-Citizens in an interconnected and polycentric world. European Union Institute for Security Studies. Brussels: European Strategy and Policy Analysis System. doi:10.2815/27508

43. Derbyshire, J., \& Wright, G. (2014). Preparing for the future: Development of an 'antifragile' methodology that complements scenario planning by omitting causation. Technological Forecasting \& Social Change, 82, 215-225.

44. DOI, U. D. (2012). Strategic Sciences Group. Retrieved from US Department of the Interior: https://www.doi.gov/strategicsciences

45. Dortmans, P. J. (2005). Forecasting, backcasting, migration landscapes and strategic planning maps. Futures, 37(4), 273-285. doi: 10.1016/j.futures.2004.07.003

46. Dreborg, K. H. (2002). Scenarios and structural uncertainty: Explorations in the field of sustainable transport. Kungliga Tekniska Hogskolan, Department of Infrastructure. Stockholm: Royal Institute of Technology. Retrieved from: https://elibrary.ru/item.asp?id=8873517

47. Dror, Y. (1988). Uncertainty: Coping with it and with political feasibility. In H. J. Miser, \& E. S. Quade (Eds.), Handbook of Systems Analysis: Craft Issues and Procedural Choices (pp. 247-281). New York: John Wiley \& Sons.

48. Duckett, D. G., Sutherland, L. A., Kyle, C., Boden, L. A., Auty, H., Bessell, P. R., \& McKendrick, I. J. (2017). Scenario planning as communicative action: Lessons from participatory exercises conducted for the Scottish livestock industry. Technological Forecasting and Social Change, 114, 138-151. doi: 10.1016/j.techfore.2016.07.034

49. Ducot, G., \& Lubben, G. J. (1980). A typology for scenarios. Futures, 12(1), 51-57. doi: 10.1016/S0016-3287(80)80007-3

50. Dufva, M., \& Ahlqvist, T. (2015). Knowledge creation dynamics in foresight: A knowledge typology and exploratory method to analyse foresight workshops. Technological Forecasting \& Social Change, 94, 251-268. doi: 10.1016/j.techfore.2014.10.007

51. Durance, P., \& Godet, M. (2010). Scenario building: Uses and abuses. Technological Forecasting and Social Change, 77, 1488-1492. doi: 10.1016/j.techfore.2010.06.007

52. Ellis, B., \& Brigham, L. (2009). Arctic Marine Shipping Assessment 2009 Report, 2nd printing. Arctic Council. Arctic Council's Protection of the Arctic Marine Environment (PAME). Retrieved from http://hdl.handle.net/11374/54

53. Eppen, G. D., Martin, R. K., \& Schrage, L. (1989). A scenario approach to capacity planning. Operations Research, 37(4), 517-527. Retrieved from https://www.jstor.org/stable/171252

54. Erdmann, L., \& Hilty, L. M. (2010). Scenario analysis: Exploring the macroeconomic impacts of information and communication technologies on greenhouse gas emissions. Journal of Industrial Ecology, 14(5), 826-843. doi: 10.1111/j.1530-9290.2010.00277.x

55. Eriksson, E. A. (2004). Scenario-based methodologies for strategy development and management of change. In O. Mats-Olov, \& G. Sjöstedt (Eds.), Systems Approaches and Their Application: Examples from Sweden (pp. 167-194). Dordrecht: Kluwer Academic Publishers. ISBN: 1-4020-2369-3

56. Fauré, E., Arushanyan, Y., Ekener, E., Miliutenko, S., \& Finnveden, G. (2017). Methods for assessing future scenarios from a sustainability perspective. European Journal of Futures Research, 5(17), 1-20. doi: 10.1007/s40309-017-0121-9

57. FEMA, F. E. (2018). National Level Exercise 2018. Department of Homeland Security. Washington, DC: FEMA. Retrieved from https://www.fema.gov/nle

58. Gallopín, G. C., \& Raskin, P. D. (2002). Global Sustainability: Bending the Curve. London: Routledge. ISBN: 0-415-26592-4

59. Gardner, W. L., \& Martinko, M. J. (1996). Using the myers-briggs type indicator to study managers: A literature review and research agenda. Journal of Management, 22(1), 45-83. doi: $10.1177 / 014920639602200103$ 
60. Gersick, C. J. (1991). Revolutionary change theories: A multilevel exploration of the punctuated equilibrium paradigm. Academy of Management Review, 16(1), 10-36. doi: 10.5465/amr.1991.4278988

61. Glenn, J. C. (1998). 2050 Global Work/Technology Scenarios. The Millennium Project. Retrieved from: http://www.millennium-project.org/

62. Glenn, J. C., \& Gordon, T. J. (2000). Millennium 3000 scenarios. In State of the Future at the Millennium. ISBN 0-9657362-6-1

63. Godet, M. (1987). Scenarios and Strategic Management. London: Butterworth.

64. Godet, M., \& Roubelat, F. (1996). Creating the future: The use and misuse of scenarios. Long Range Planning, 29, 164-171. doi: 10.1016/0024-6301(96)00004-0

65. Goens, G. A. (1999). Beyond Data: The World of Scenario Planning. Alexandria, VA: American Association of School Administrators. Retrived from: http://www.aasa.org/

66. Gordon, A. (2011). The uses and limits of visionary scenarios: learning from the African experience. Foresight, 13(4), 64-81. doi:10.1108/14636681111153977

67. Gordon, T. J. (1994a). Cross-impact method. American Council for the United Nations University.

68. Gordon, T. J. (1994b). Trend impact analysis. AC/UNU Millennium Project. Futures research methodology.

69. Grevi, G., Keohane, D., Lee, B., \& Lewis, P. (2013). Empowering europe's future: Governance, power and options for the EU in a changing world. Chatham House \& FRIDE. ESPAS.

70. Gros, D., \& Alcidi, C. (2013). The global economy in 2030: Trends and strategies for europe. Brussels: European Strategy and Policy Analysis Systems.

71. Haeffner, M., Leone, D., Coons, L., \& Chermack, T. (2012). The effects of scenario planning on participant perceptions of learning organization characteristics. Human Resources Development Quarterly, 23(4), 519-542. doi: 10.1002/hrdq

72. Heugens, P. P., \& van Oosterhout, J. (2001). To boldly go where no man has gone before: Integrating cognitive and physical features in scenario studies. Futures, 33, 861-872. doi: 10.1016/S00163287(01)00023-4

73. Hodgkinson, G. P., \& Clarke, I. (2007). Exploring the cognitive significance of organizational strategizing: A dual-process framework and research agenda. Human Relations, 60(1), 243-255. doi: $10.1177 / 0018726707075297$

74. Hodgkinson, G., \& Healey, M. (2008). Towards a (pragmatic) science of strategic intervention: design propositions for scenario planning. Organization Studies, 29(3), 435-457. doi: 10.1177/0170840607088022

75. Hoorens, S., Ghez, J., Guerin, B., Schweppenstedde, D., Hellgren, T., Horvath, V., . . Kobzar, S. (2013). Europe's societal challenges: An analysis of global societal trends to 2030 and their impact on the EU. Brussels: RAND Europe.

76. Hopkins, M. C., Adams, M. J., Super, P. E., Olson, D. H., Hickman, C. R., English, P., . . Ludwig, K. (2018). Batrachochytrium salamandrivorans (bsal) in Appalachia: Using scenario building to proactively prepare for a wildlife disease outbreak caused by an invasive amphibian chytrid fungus. Reston, VA: U.S. Geological Survey Report.

77. Hunt, D. V., Lombardi, D. R., Barber, A. R., Barnes, M., Boyko, C. T., \& al., e. (2012). Scenario archetypes: Converging rather than diverging themes. Sustainability, 4(4), 740-772. doi:10.3390/su4040740

78. Huss, W. R., \& Honton, E. J. (1987). Scenario planning-What style should you use? Long Range Planning, 20(4), 21-29. doi: 10.1016/0024-6301(87)90152-X

79. Inayatullah, S. (1993). From 'who am i?' to 'when am i?': Framing the shape and time of the future. Futures, 25(3), 235-253. doi: 10.1016/0016-3287(93)90135-G

80. Inayatullah, S. (2008). Six pillars: Futures thinking for transforming. Foresight, 10(1), 4-21. doi: $10.1108 / 14636680810855991$

81. International, S. (2019). Scenario Planning. California. 
82. Iwaniec, D. M., Childers, D. L., VanLehn, K., \& Wiek, A. (2014). Studying, teaching and applying sustainability visions using systems modeling. Sustainability, 6, 4452-4469. doi:10.3390/su6074452

83. Jefferson, T., \& Preston, A. (2005). Australia's "other" gender wage gap: Baby boomers and compulsory superannuation accounts. Feminist Economics, 11(2), 79-101. doi: $10.1080 / 13545700500115902$

84. Johnson, P. A., \& Sieber, R. E. (2011). Negotiating constraints to the adoption of agent-based modeling in tourism planning. Environment and Planning B: Planning and Design, 38, 307-321. doi:10.1068/b36109

85. Kahn, H., \& Weiner, A. J. (1967). The year 2000: A Framework for Speculation on the Next ThirtyThree Years. Macmillan.

86. Kahn, H., Brown, W., \& Martel, L. (1976). Next 200 years: A scenario for America and the world. NY: William Morrow \& Company, Inc.

87. Keough, S. M., \& Shanaha, K. J. (2008). Scenario planning: Toward a more complete model for practice. Advances in Developing Human Resources, 10(2), 166-178. doi: 10.1177/1523422307313311

88. Klein, H. E., \& Linneman, R. E. (1981). The use of scenarios in corporate planning - eight case histories. Long Range Planning, 14(5), 69-77. doi: 10.1016/0024-6301(81)90010-8

89. Kosko, B. (1997). Fuzzy Engineering. New Jersey: Prentice-Hall Inc.

90. Kosow, H., \& Gaßner, R. (2008). Methods of future scenario analysis: Overview, assessment, and selection criteria. Deutsches Institut für Entwicklungspolitik. Bonn, Germany: DIE Research Project "Development Policy: Questions for the Future". Retrieved from: http://www.die-gdi.de

91. Kuhn, K. M., \& Sniezek, J. A. (1996). Confidence and uncertainty in judgmental forecasting: Differential effects of scenario presentation. Journal of Behavioral Decision Making, 231-247. doi: 10.1002/(SICI)1099-0771(199612)9:4<231::AID-BDM240>3.0.CO;2-L

92. Leschine, T. M., Pavia, R., Walker, A. H., Bostrom, A., \& Starbird, K. (2015). What-if scenario modeling to support oil spill preparedness and response decision-making. Human and Ecological Risk Assessment: An International Journal, 21(3), 646-666. doi: 10.1080/10807039.2014.947868

93. Lincoln, Y. S., \& Guba, E. G. (1985). Naturalistic Inquiry. Newbury Park, CA: Sage.

94. Lindgren, M., \& Bandhold, H. (2003). Scenario Planning: The link between future and strategy. Houndmills, UK: Palgrave Macmillan.

95. Linneman, R. E., \& Klein, H. E. (1979). The use of multiple scenarios by US industrial companies. Long Range Planning, 12, 83-90. doi: 10.1016/0024-6301(79)90034-7

96. List, D. (2005). Scenario network mapping: The development of a methodology for social inquiry. University of South Australia.

97. Machlis, G., \& McNutt, M. K. (2010). Scenario-building for the Deepwater Horizon oil spill. Science, 329(5995), 1018-1019. doi: 10.1126/science.1195382

98. Mackay, B., \& McKiernan, P. (2018). Scenario Thinking: A Historical Evolution of Strategic Foresight. Cambridge: Cambridge University Press.

99. Mago, V. K., Morden, H. K., Fritz, C., Wu, T., Namazi, S., Geranmayeh, P., . . Dabbaghian, V. (2013). Analyzing the impact of social factors on homelessness: a Fuzzy Cognitive Map approach. BMC Medical Informatics and Decision Making, 13, 94. doi: 10.1186/1472-6947-13-94

100.March, J. G. (1991). Exploration and exploitation in organizational learning. Organization Science, 2(1), 71-88. doi: 10.1287/orsc.2.1.71

101. Martelli, A. (2001). Scenario building and scenario planning: State of the art and prospects of evolution. Futures Research Quarterly, 17, 57-70. doi: 10.1108/14636680710727516

102. Masini, E. B., \& Vasquez, J. M. (2000). Scenarios as seen from a human and social perspective. Technological Forecasting and Social Change, 65(1), 49-66. doi: 10.1016/S0040-1625(99)00127-4

103.McCrae, R. R., \& Costa Jr, P. T. (1989). Reinterpreting the Myers-Briggs Type Indicator from the perspective of the five-factor model of personality. Journal of Personality, 57(1), 17-40. Retrieved from: https://www.ncbi.nlm.nih.gov/pubmed/2709300 
104.Meissner, P., \& Wulf, T. (2013). Cognitive benefits of scenario planning: its impact on biases and decision quality. Technological Forecasting \& Social Change, 80, 801-814. doi: 10.1016/j.techfore.2012.09.011

105.Migration Data Portal. (2017). Migration forecasting. International Organization for Migration, Global Migration Data Analysis Centre (GMDAC), Berlin, DE.

106. Millet, S. M. (2003). The future of scenarios: Challenges and opportunities. Journal of Strategy and Leadership, 31(2), 16-24. doi: 10.1108/10878570310698089

107. Mintzberg, H. (1994). The fall and rise of strategic planning. Harvard Business Review, 72(1), $107-$ 114.

108.Mitroff, I. I., \& Emshoff, J. R. (1979). On strategic assumption-making: A dialectical approach to policy and planning. Academy of Management Review, 4(1-12). doi: 10.5465/amr.1979.4289165

109. Montibeller, G., Gummer, H., \& Tumidei, D. (2006). Combining scenario planning and multi-criteria decision analysis in practice. Journal of Multi-Criteria Decision Analysis, 14(1-3), 5-20. doi: 10.1002/mcda.403

110.Moyer, K. (1996). Scenario planning at British Airways - A case study. Long Range Planning, 29(2), 172-181. doi: 10.1016/0024-6301(96)00005-2

111.NASA. (2019). Hypothetical Comet Impact Scenario - PDC 2019. Retrieved from Center for Near Earth Object Studies: https://cneos.jpl.nasa.gov/pd/cs/pdc19c/

112.NISTEP Report. (2001). The seventh technology foresight-future technology in Japan towards the year 2030. vol. 71, National Institute of Science and Technology Policy (Japan), Science and Technology Forecast Center.

113. Ogilvy, J. A., \& Mandel, T. (1984). How to construct and use scenarios. SRI International. Menlo Park, California.

114.Omgevingsbeleid, S. T. (2000). Terugblik op toekomstverkenningen. The Hague: Netherlands Scientific Council for Government Policy (WRR). Retrieved from https://www.wrr.nl/publicaties/publicaties/2000/10/24/terugblik-op-toekomstverkenningen

115.Parson, E. A., Burkett, V., Fisher-Vanden, K., Keith, D., Mearns, L., Pitcher, H., ... Webster, M. (2007). Global-change scenarios: Their development and use. Synthesis and Assessment Products, 2.1b, Climate Change Science Program, Washington, D.C.

116.Paul, A. M. (2004). The cult of personality testing: How personality tests are leading us to miseducate our children, mismanage our companies, and misunderstand ourselves. New York: Free Press.

117.Phadnis, S., Caplice, C., Sheffi, Y., \& Singh, M. (2015). Effect of scenario planning on field experts' judgment of long-range investment decisions. Strategic Management Journal, 1401-1411. doi: 10.1002/smj.2293

118.Phelps, R., Chan, C., \& Kapsails, S. C. (2001). Does scenario planning affect performance? Two exploratory studies. Journal of Business Research, 51, 223-232. doi: 10.1016/S0148-2963(99)00048-X

119.Pipher, J. (2014). Informing water use planning with consumer preferences: a case study in Kelowna, B.C. Simon Fraser University, School of Resource and Environmental Management Faculty of the Environment, BC.

120.Pulver, S., \& VanDeveer, S. (2007). Futurology and futurizing: A research agenda on the practice and politics of global environmental scenarios. Amsterdam Conference on the Human Dimensions of Global Environmental Change "Earth Systems Governance: Theories and Strategies for Sustainability”, (pp. 1-22). Amsterdam, Netherlands.

121.Ramirez, R., \& Selin, C. (2014). Plausibility and probability in scenario planning. Foresight, 16(1), 5474. doi: 10.1108/FS-08-2012-0061

122.Ramírez, R., \& Wilkinson, A. (2014). Re-thinking the 2 X2 scenario method: Grid or frames? Technological Forecasting and Social Change, 86, 254-264. doi: 10.1016/j.techfore.2013.10.020

123. Rawluk, A., \& Godber, A. (2011). Widening the scope of scenario planning in small communities: A case study use of an alternative method. Ecology and Society, 16(1), 11. Retrieved from http://www.ecologyandsociety.org/vol16/iss1/art11/ 
124.Riede, F. (2006). The Scandinavian connection: The roots of Darwinian archaeology in 19th-century Scandinavian archaeology. University of Cambridge, Department of Archaeology. England: Bulletin of the History of Archaeology.

125.Ringland, G. (2006). Scenario Planning: Managing for the Future (2nd ed.). Chichester: Wiley.

126.Schnaars, S. P. (1987). How to develop and use scenarios. Long Range Planning, 20(1), 105-114. doi: 10.1016/0024-6301(87)90038-0

127.Schoemaker, P. J. (1993). Multiple scenario development: Its conceptual and behavioral foundation. Strategic Management Journal, 14, 193-213. doi: 10.1002/smj.4250140304

128. Schultz, W. (2015). Crazy futures: Why plausibility is maladaptive. 1-13. doi: 10.13140/RG.2.1.2897.9921.

129.Schwab, P., Cerutti, F., \& von Reibnitz, U. H. (2003). Foresight - Using scenarios to shape the future of agricultural research. Foresight, 5, 55-61. doi: 10.1108/14636680310471299

130.Shearer, A. W. (2005). Approaching scenario-based studies: three perceptions about the future and considerations for landscape planning. Environment and Planning B: Planning and Design, 32, 67-87. doi: $10.1068 / \mathrm{b} 3116$

131.Simon, H. A. (1972). Theories of bounded rationality. In C. B. McGuire, \& R. Radner (Eds.), Decision and organization: A volume in honor of Jacob Marschak. Amsterdam: North-Holland Publishing Company.

132. Simpson, D. G. (1992). Key lessons for adopting scenario planning in diversified companies. Planning Review, 20(3), 10-48. doi: 10.1108/eb054355

133.Smith, K. B. (2002). Typologies, taxonomies, and the benefits of policy classification. Policy Studies Journal, 30(3), 379-395. doi: 10.1111/j.1541-0072.2002.tb02153.x

134.Soros, G. (2013). Fallibility, reflexivity, and the human uncertainty principle. Journal of Economic Methodology, 20(4), 309-329. doi: 10.1080/1350178X.2013.859415

135.Spaniol, M. J., \& Rowland, N. J. (2018a). Defining scenario. Futures \& Foresight Science, 1(1), 1-13. doi: $10.1002 / \mathrm{ffo} 2.3$

136.Spaniol, M. J., \& Rowland, N. J. (2018b). The scenario planning paradox. Futures, 95, 33-43. doi: 10.1016/j.futures.2017.09.006

137. Stewart, C. C. (2008). Integral scenarios: Reframing theory, building from pracKce. Futures, 40(2), 160-172. doi: 10.1016/j.futures.2007.11.013

138. Ströh, U. M. (2004). An experimental study of organisational change and communication management. Pretoria, SA: University of Pretoria.

139. Strangert, P. (1974). Information, Uncertainty and Adaptive Planning. Stockholm: Swedish Defence Research Institute.

140.Strangert, P. (1977). Adaptive planning and uncertainty resolution. Futures, 9(1), 32-44. doi: 10.1016/0016-3287(77)90050-7

141.Taleb, N. N. (2012). AntiFragile. London: Allen Lane.

142. Teufel, B., Erdmann, L., Schirrmeister, E., aimer, S., Larendo, P., Schoen, A., . . T., L. (2013). VERA (Forward Visions on the European Research Area). Karlsruhe, Paris, Helsinki: ERA Scenario Report.

143.USFA, U. F. (2018). Scenario-based interactive firefighter training. FEMA.

144.van de Riet, O., Aazami, O., \& van Rhee, C. G. (2008). Scenario analysis and the adaptive approach: superfluous or underused in transport infrastructure planning? 2008 First International Conference on Infrastructure Systems and Services: Building Networks for a Brighter Future (INFRA) (pp. 1-6). Rotterdam: IEEE. doi: 10.1109/INFRA.2008.5439583

145.van Der Fels-Klerx, I. H., Goossens, L. H., Saatkamp, H. W., \& Horst, S. H. (2002). Elicitation of quantitative data from a heterogeneous expert panel: formal process and application in animal health. Risk Analysis, 22(1), 67-81. doi: 10.1111/0272-4332.t01-1-00007

146.van der Heijden, K. (1998). Scenarios: The Art of Strategic Conversation. New York: John Wiley. 
147.van der Heijden, K., Bradfield, R., Burt, G., Cairns, G., \& Wright, G. (2002). The Sixth Sense: Accelerating Organzsational Learning with Scenarios. West Sussex: John Wiley \& Sons.

148.van Notten, P. W., Rotmans, J., van Asselt, M. B., \& Rothman, D. S. (2003). An updated scenario typology. Futures, 35, 423-443. doi:10.1016/S0016-3287(02)00090-3

149. Van 't Klooster, S., \& van Asselt, M. (2006). Practicing the scenario-axis technique. Futures, 38(1), 1530. doi:10.1016/j.futures.2005.04.019

150.Volkery, A., \& Riberio, T. (2009). Scenario planning in public policy: Understanding use, impacts and the role of institutional context factors. Technological Forecasting \& Social Change, 76, 1198-1207. doi:10.1016/j.techfore.2009.07.009

151.von der Gracht, H. A. (2008). The future of logistics: Scenarios for 2025. Wiesbaden, Germany: Springer Science \& Business Media.

152.Wack, P. (1985a). Scenarios: Shooting the rapids. Harvard Business Review, 139-150. Retrieved from https://hbr.org/1985/11/scenarios-shooting-the-rapids

153.Wack, P. (1985b). Scenarios: Uncharted waters ahead. Harvard Business Review, 73-89. Retrieved from https://hbr.org/1985/09/scenarios-uncharted-waters-ahead

154. Wilkinson, A. (2009). Scenarios practices: In search of theory. Journal of Futures Studies, 13(3), 107114. Retrieved from: https://jfsdigital.org/articles-and-essays/2009-2/vol-13-no-3-february/scenariosymposium/scenarios-practices-in-search-of-theory/

155.Wilkinson, A., \& Eidinow, E. (2008). Evolving practices in environmental scenarios: a new scenario typology. Environmental Research Letters, 3, 1-11. doi:10.1088/1748-9326/3/4/045017

156.Wilkinson, A., Kupers, R., \& Mangalagiu, D. (2013). How plausibility-based scenario practices are grappling with complexity to appreciate and address 21 st century challenges. Technological Forecasting \& Social Change, 80, 699-710. doi: 10.1016/j.techfore.2012.10.031

157.Wilson, I. (1998). Mental maps of the future: An intuitive logics approach to scenarios. In L. Fahey, \& R. Randall (Eds.), Learning from the Future: Competitive Foresight Scenarios (pp. 81-108). NY: John Wiley \& Sons.

158.Wilson, I. H. (1978). Scenarios. In J. Fowled (Ed.), Handbook of Futures Research (pp. 22-47). CT: Greenwood Press.

159. Wollenberg, E., Edmunds, D., \& Buck, L. (2000). Using scenarios to make decisions about the future: Anticipatory learning for the adaptive co-management of community forests. Landscape and Urban Planning, 47(1-2), 65-77.

160. Worthington, W. J., Collins, J. D., \& Hitt, M. A. (2009). Beyond risk mitigation: Enhancing corporate innovation with scenario planning. Business Horizons, 52, 441-450. doi:10.1016/j.bushor.2009.04.008

161.Wright, G., \& Cairns, G. (2011). Scenario Thinking: Pracitcal Approaches to the Future. Hampshire: Palgrave Macmillan.

162.Wright, G., Bradfield, R., \& Cairns, G. (2013). Does the intuitive logics method - and its recent enhancements - produce "effective" scenarios? . Technological Forecasting \& Social Change, 80, 631-642. doi: 10.1016/j.techfore.2012.09.003

163.Wright, G., Cairns, G., \& Goodwin, P. (2009). Teaching scenario planning : Lessons from practice in academe and business. European Journal of Operational Research, 194(1), 323-335. doi: 10.1016/j.ejor.2007.12.003

164.Wright, G., Cairns, G., O'Brien, F. A., \& Goodwin, P. (2018). Scenario analysis to support decision making in addressing wicked problems: Pitfalls and potential. European Journal of Operational Research, 1-17. doi: 10.1016/j.ejor.2018.08.035

165.Wright, G., van der Heijden, K., Burth, G., Bradfield, R., \& Cairns, G. (2008). Scenario planning interventions in organizations: An analysis of the causes of success and failure. Futures, 40(3), 218236. doi: 10.1016/j.futures.2007.08.019

166. Yaniv, I. (2011). Group diversity and decision quality: Amplification and attenuation of the framing effect. International Journal of Forecasting, 27, 41-49. doi:10.1016/j.ijforecast.2010.05.009

167.Zentner, R. D. (1975). Scenarios in forecasting. Chemical and Engineering News, 22-34 
Table 1. CSI typology table.

\begin{tabular}{|c|c|c|c|}
\hline Section & Characteristic & Category & Sub-category \\
\hline \multirow[t]{9}{*}{$\begin{array}{l}\text { Section 1: } \\
\text { Project Goal }\end{array}$} & Epistemology & $\begin{array}{l}\text { Cartesian } \\
\text { Non-cartesian }\end{array}$ & \\
\hline & Control & $\begin{array}{l}\text { Passive } \\
\text { Reactive } \\
\text { Preactive } \\
\text { Proactive } \\
\text { Reflexive }\end{array}$ & \\
\hline & Value/Reality & $\begin{array}{l}\text { Descriptive } \\
\text { Normative } \\
\text { Dynamic }\end{array}$ & $\begin{array}{l}\text { Hypothetical } \\
\text { Plausible } \\
\text { Active } \\
\text { Passive }\end{array}$ \\
\hline & Vantage Point & $\begin{array}{l}\text { Forward-casting } \\
\text { Backcasting } \\
\text { Bi-directional }\end{array}$ & $\begin{array}{l}\text { Likely futures } \\
\text { What-if } \\
\text { Ideal futures } \\
\text { Crisis focused } \\
\text { Hedging } \\
\text { Selective }\end{array}$ \\
\hline & Motivation & $\begin{array}{l}\text { Preserving } \\
\text { Transforming }\end{array}$ & \\
\hline & $\begin{array}{l}\text { Application } \\
\text { Subject }\end{array}$ & $\begin{array}{l}\text { Generic } \\
\text { Specific } \\
\text { Issue-based } \\
\text { Area-based } \\
\text { Institutional-based } \\
\text { Cross-based }\end{array}$ & \\
\hline & Variable Scale & $\begin{array}{l}\text { External } \\
\text { Internal } \\
\text { Policy } \\
\text { Multi-scale }\end{array}$ & \\
\hline & Horizon & $\begin{array}{l}\text { Short-term } \\
\text { Medium-term } \\
\text { Long-term } \\
\text { Congruent }\end{array}$ & \\
\hline & Geographic Scope & $\begin{array}{l}\text { Global } \\
\text { Supranational } \\
\text { National } \\
\text { Regional } \\
\text { Local } \\
\text { Overlapping }\end{array}$ & \\
\hline $\begin{array}{l}\text { Section 2: } \\
\text { Process Design }\end{array}$ & Practitioners & $\begin{array}{l}\text { Facilitators } \\
\text { Problem owners } \\
\text { Employees } \\
\text { Experts }\end{array}$ & $\begin{array}{l}\text { Inhouse } \\
\text { Remarkable people }\end{array}$ \\
\hline
\end{tabular}


Community

Stakeholders

Cross-populations

Groups

Data

Data Collection

Resources

Institutional Conditions

Temporal Nature

Scenario Content

Complexity

Integration

Theme

Dynamics

Validation

Variable Mixture

Variable Types
Homogeneous

Heterogeneous

Quantitative

Qualitative

Complimenting

Participatory

Desk-research

Blended

Dynamic modelling

Extensive

Limited

Complex

Open

Constrained

Structured

Chain

Snapshot

Varied

Low

High

Low

High

Growth

Collapse

Discipline

Transformational

Wild card

Peripheral

Trend

Compound

Scenario-level

Model-level

Combination

Intradisciplinary Interdisciplinary

Critical uncertainties

Predetermined

Unspecified uncertainties
Plausibility

Internal consistency

Relevance

Transparency

Novelty

Bootstrapping

Goodness of fit

Intuition

Novel insights 
Deviation

Quantity

Section 4:

Scenario Impact

Decision Makers

Organisational Capacity

Uncertainty Strategy

Implementation
Conventional

Alternative

Two

Greater than two

Within

Outwith

Collaboration

Engagement

Abandonment

Selective Adoption

Dynamic

Static

Adaptive

Fixed

Flexible

Quasi-static

Hedging

Signposting

Business-as-usual

Transformational
Structured

Semi-structured Unstructured 
Fig. 1. Ducot and Lubben's (1980) exploratory (1a) and anticipatory (1b) scenario spaces.

1a

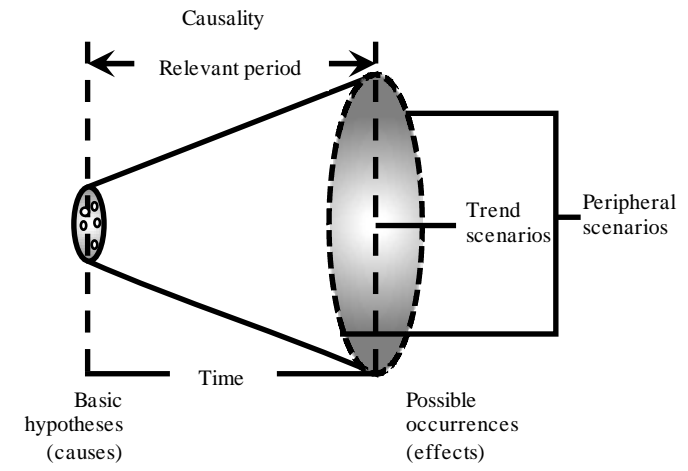

$1 b$

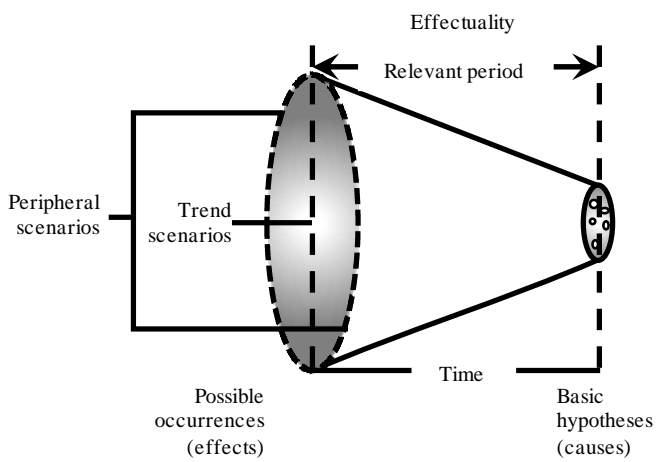

Note: Trend scenarios are represented by the lighter area in the middle of the cone. Peripheral scenarios are represented by the darker area that spreads out to the edges of the cone.

Fig. 2. Ducot and Lubben's (1980) mid-mixed (2a) and end-mixed (2b) scenario spaces.

$2 \mathrm{a}$

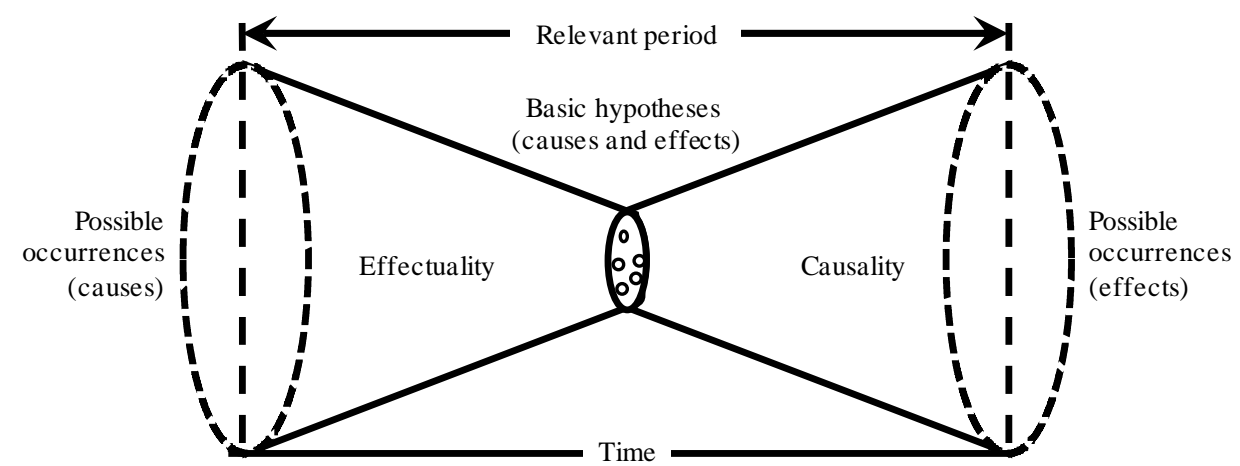

$2 b$

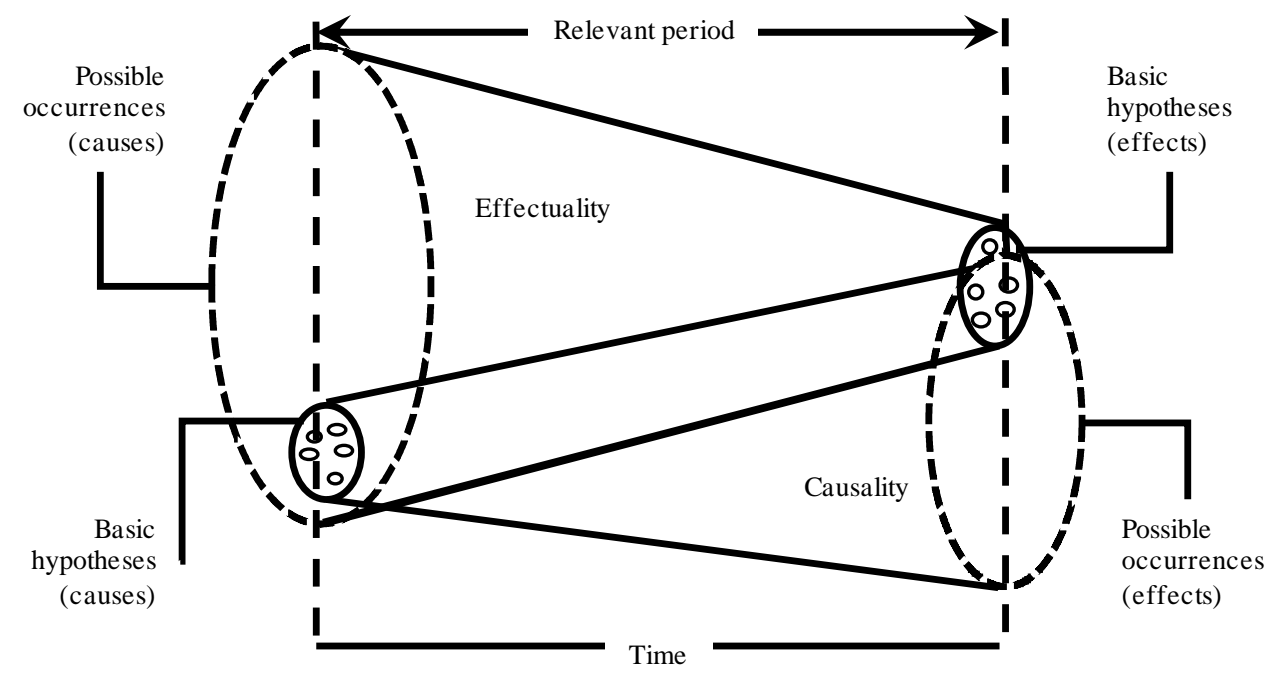




\section{Appendix A}

Table 2. SP interventions used to test the CSI typology parameters.

\begin{tabular}{lll}
\hline Project & Summary & Reference \\
\hline
\end{tabular}

Tasmania Case

Global Trends 2030

RAND Europe - Europe's Societal Challenges

Arctic Council's Arctic Marine Shipping Assessment

Deepwater Horizon oil spill

US Geological Survey Appalachian (Bsal) scenarios

Defence industry

Sweden's future crime arena

Australia's gender pay gap

Migration forecasting

Global-Change Scenarios
The aim was to explore the potential role of unions in supporting regional regeneration in North West Tasmania.

The aim was to explore the possibility of establishing "an inter-institutional system identifying long-term trends on major policy issues facing the EU'.

Part of the ESPAS projects, the goals were to assess global trends and develop policy responses across EU institutions, spanning 2014-2019.

Extensive assessments, workshops, and interviews to understand clearly the uncertainties that might shed light on the determinants of future Arctic marine operations.

U.S. Department of the Interior established a Strategic Sciences Working Group to provide rapid scientific assessment of potential consequences of the spill that could provide usable knowledge to decision-makers.

Scenario planning facilitated brainstorming sessions to produce cascading consequences (social, economic, and ecological) of a $\mathrm{Bsal}$ disease outbreak in the Appalachian region.

SP method of articulating migration landscapes to connect forecasting and backcasting efforts in order to realise a desired end-state.

A short-run scenario workshop with a small team of public representatives carried out to understand more deeply the logic of the future crime arena.

Data of past and present trends are used to inform two scenarios of future trends in employment and pay gap.

Mixed data scenarios that provide informed guesses about future migration flows and trends to inform policy, programmes, and resource allocation.

Scenarios aimed at providing current evaluations of climate change science to inform public debate, policy, and operational decisions.
(Cairns, Wright, Fairbrother, \& Phillips, 2017)

(de Vasconcelos, Grevi, Peral, \& Zanders, 2012, p. 5)

(Hoorens, et al., 2013)

(Ellis \& Brigham, 2009)

(Machlis \& McNutt, 2010)

(Hopkins, et al., 2018)

(Dortmans, 2005)

(Lindgren \& Bandhold, 2003)

(Jefferson \& Preston, 2005)

(Migration Data Portal, 2017)

(Parson, et al., 2007)

(continued on next page) 
Next 200 Years: A Scenario for America and the World

Empowering Europe's Future

National Level Exercise 2018

NASA - Hypothetical Comet Impact Scenario - PDC 2019

Kuna Yala case study

The future of logistics: Scenarios for 2025

25 by 25 policy

Informing water use planning with consumer preferences: a case study in Kelowna, B.C.

The seventh technology foresight - future technology in Japan towards the year 2030

The Trend Report

VERA

Digital Futures Final Report

Global Europe 2050
A series of highly complex, forecasting scenarios exploring society, culture,

(Kahn, Brown, \& Martel, economics, industry and more for the next 200 years.

An extensive project to help inform governance, power, and options for the EU by 2030 .

National level scenario-based exercises with large heterogeneous practitioners who examine the ability of all levels protect against, respond to, and recover from a major Mid-Atlantic hurricane.

A hypothetical "worst case" comet impact scenario for a long-period comet to create plausible, technically realistic storylines.

Cases study of implementing alternative scenario methods for cross-community collaborations when cultural norms traditionally prevent such efforts.

A study of scenario techniques used to present futures of the logistics service industry to establish flexibility, creativity, and the ability to adapt to changes quickly.

The scenario discovery model was used to lead practitioners through discovering the potential impacts of renewable energy requirements to produce $25 \%$ of energy from renewable sources by 2025 .

Scenario intervention to promote water efficient residential landscaping practices by exploring the psychology behind residents' water use decisions, and to improve understanding of drivers of residential water demand.

Conducted a technology forecast survey to inform scenarios that projected the future direction of technology in Japan from a long-term viewpoint.

Conducted for ESPAS, this report presents findings of research on global economic trends up to the year 2030 and how they could affect Europe.

Four scenarios aimed to provide relevant strategic intelligence for the future governance and priority-setting of the RTDI system in Europe.

Scenarios exploring the potential interactions between different areas of technology, human life and global resources, and the role of digital technologies, to the $2030-2050$ time horizons

Scenario planning using a highly participatory approach combining visionary
1976)

(Grevi, Keohane, Lee, \& Lewis, 2013)

(FEMA, 2018)

(NASA, 2019)

(Rawluk \& Godber,

(von der Gracht, 2008)

(Bryant \& Lempert, 2010)

(Pipher, 2014)

(NISTEP Report, 2001)

(Gros \& Alcidi, 2013)

(Teufel, et al., 2013)

(CNECT, 2016)

(Commission, 2011)

(continued on next page) 
The Year 2000: A framework for speculation on the next thirtythree years

Global Warming of $1.5^{\circ} \mathrm{C}$

British Airways case study

Dutch transportation infrastructure policy evaluation

Equalities and Human Rights Advisory Group thinking with plausibility to combine the global perspective with a specific focus on the future of European integration.

An extensive series of scenarios imagining what the world may be like over the next 33 years.

The report provides future impacts of global warming of $1.5^{\circ} \mathrm{C}$ - above preindustrial levels - and greenhouse gas emission pathways, as contained in the Decision of the 21st Conference of Parties of the United Nations Framework Convention on Climate Change to adopt the Paris Agreement.

Part of VRVR typology's 18 case studies. "a 1994 explorative scenario analysis that examined societal developments and their implications for the airline industry."

Part of the development of the VAV typology, to determine superfluous or underuse of scenario analysis and adaptive approaches to assess policy in the transportation infrastructure industry.

The Scottish Government initiative to crowdsource knowledge from third-sector organisations to improve policy development and implementation.
(Kahn \& Weiner, 1967)

(de Coninck, et al., Strengthening and implementing the global response, 2018)

(Moyer, 1996)

(van Notten, Rotmans, van Asselt, \& Rothman, 2003, p. 435)

(van de Riet, Aazami, \& van Rhee, 2008)

(Audit Scotland, 2019)

Table 3. Novel scenario planning methods used to test the CSI typology parameters.

\begin{tabular}{|c|c|c|}
\hline Project & Summary & Reference \\
\hline Reference Scenarios & $\begin{array}{l}\text { The purpose of these scenarios is to } \\
\text { identify past and present trends then to } \\
\text { project them into the future for explorative } \\
\text { understanding. }\end{array}$ & (Ackoff, 1981) \\
\hline ALIVE & $\begin{array}{l}\text { A scenario-based training program based } \\
\text { on collaborations with National Institute of } \\
\text { Standards and Technology, Chicago Fire } \\
\text { Dept, and FDNY. }\end{array}$ & (USFA, 2018) \\
\hline Critical Scenario Method & $\begin{array}{l}\text { The study applies the Critical Scenario } \\
\text { Method to explore different possible and } \\
\text { plausible futures for the ship-breaking } \\
\text { industry globally and locally. }\end{array}$ & (Cairns, 2014) \\
\hline $\begin{array}{l}\text { Case study 1: the English } \\
\text { provincial broker's future }\end{array}$ & $\begin{array}{l}\text { Scenario planning with multi-criteria } \\
\text { decision analysis (SPMCDA) support was } \\
\text { used to help the client ensure that their } \\
\text { chosen strategic direction best suited their } \\
\text { goals and aspirations. }\end{array}$ & $\begin{array}{l}\text { (Montibeller, Gummer, } \\
\text { \& Tumidei, 2006) }\end{array}$ \\
\hline $\begin{array}{l}\text { Case study 2: the warehouse } \\
\text { development in Casemurate, Italy }\end{array}$ & $\begin{array}{l}\text { SPMCDA was used to help the client } \\
\text { determine the uncertainties with planning }\end{array}$ & (continued on next page) \\
\hline
\end{tabular}


permission for zoning revisions of farm land to warehouse development.

MSG

GM - A scenario approach to capacity planning
Experimenting with a method of generating a very wide range of futures to facilitate thinking broadly and open-mindedly about what may lie ahead upon which to base strategic planning.

A scenario model was developed for GM to aid in making decisions about capacity for four of their auto lines.
(Davis, Bankes, \&

Egner, 2007)

(Eppen, Martin, \&

Schrage, 1989)

\section{Appendix B}

Table 4. Tasmania Case SP profile.

\begin{tabular}{|c|c|c|c|}
\hline Section & Profile & Explanation & (Cairns \& Wright, 2018) \\
\hline \multirow[t]{6}{*}{$\begin{array}{l}\text { Section 1: } \\
\text { Project } \\
\text { goal }\end{array}$} & $\begin{array}{l}\text { Epistemology } \\
-\quad \text { Non-Cartesian }\end{array}$ & $\begin{array}{l}\text { The aims were to prompt articulated } \\
\text { action to achieve the jointly-held goal, } \\
\text { regeneration. }\end{array}$ & \\
\hline & Control & & \\
\hline & Conflict point & $\begin{array}{l}\text { "divergence of opinion about key } \\
\text { factors" extracted from the content } \\
\text { analysis. }\end{array}$ & (p. 232) \\
\hline & - $\quad$ Reactive & $\begin{array}{l}\text { "Our own reading of the Delphi report, } \\
\text { along with the transcripts of the first } \\
\text { rounds scenario workshops, indicated } \\
\text { that there was considerable focus on } \\
\text { decisions and events outside the region, } \\
\text { with signs that the region itself was a } \\
\text { mere 'passenger' on the journey set by } \\
\text { others... Economic matters were by } \\
\text { and large driven by outside factors, and } \\
\text { by extra costs imposed on local } \\
\text { business, such that of sea transportation } \\
\text { and agricultural produce to the major } \\
\text { markets on the mainland, in Melbourne } \\
\text { and beyond." }\end{array}$ & (p. 233) \\
\hline & - $\quad$ Preactive & $\begin{array}{l}\text { "Others, however, rejected the notion... } \\
\text { For these individuals, economic } \\
\text { resilience needed to be built around the } \\
\text { ground-up growth and nurturing of } \\
\text { small businesses within the region." }\end{array}$ & (p.233) \\
\hline & - $\quad$ Proactive & $\begin{array}{l}\text { "For some, economic resilience and } \\
\text { regeneration should come from seeking } \\
\text { a new, large incoming industry to } \\
\text { replace the major employers that had } \\
\text { closed down" }\end{array}$ & (p.233) \\
\hline
\end{tabular}


Value/reality

- Descriptive

"In both workshops, the opening

- Plausible question of participants was whether the scenario narratives were plausible and possible, which was confirmed without question in both cases."

Vantage point

- Bi-directional

"development of a set of initial extreme

(p. 232)

- Selective scenarios by the research team" then, "applying the 'backward logic' approach, participants were asked to discuss the scenarios... that would lead the future to unfold in one or the other set of outcomes."

Motivation

- $\quad$ Transforming

The intent was to prompt articulated action to initiate a process of regeneration.

Application

- $\quad$ Specific

"The full research programme was directed at exploring the potential role of unions in supporting regional regeneration in North West Tasmania."

Subject

- Cross-based

"exploring the potential role of unions in supporting regional regeneration in North West Tasmania"

Variable scale

- Multi-scale

"A total of ten theme headings were extracted from the content analysis" of two scenario workshops. The themes encompassed external (e.g. "Global conflict and instability") and internal (e.g. "Attitudes towards education, training and employment") variables.

Horizon

- $\quad$ Short-term

"What must you... do in the very near future to maximize the chances of a best-case future?"

Geographic scope

- Overlapping "we developed two macro-level global/national/state-level scenario outlines" 


\section{Section 2: $\quad$ Practitioners}

$\begin{array}{lll}\begin{array}{l}\text { Process } \\ \text { design }\end{array} & - & \text { Cross- } \\ & \text { populations }\end{array}$

\section{Groups}

- Heterogeneous

Public, private and NGOs. "The body of stakeholders included the unions that were the focus of the programme, along with senior representatives of the nine local government areas (LGAs) from the region, Tasmanian state agencies, the local government economic development agency covering the nine LGAs, the regional university campus, and local business leaders."

\section{Data}

$$
\text { - Complimenting }
$$

"semi-structured interviews" and "Delphi inquiry was conducted... participants were asked to give numeric rankings"

Data collection

- Blended

\section{Resources}

- Complex

Institutional conditions

- $\quad$ Structured

"extensive desk research" and "semistructured interviews"

Time-poor executives, and political changes, but full participation of public, private, and NGO bodies.

A set of scenarios were presented to the (pp. 231-232)

(p. 231)

(pp. 231, 233)

(p. 231) participants for exploration, then ten themes were extracted and presented in a Delphi round for ranking.

Section 3: Temporal nature

Scenario - Varied content

"participants were asked to discuss the scenarios in small groups, and to consider the driving forces in the present...that would lead the future to unfold in one or the other set of outcomes." 
Integration

- ?

Themes

- Discipline

- Collapse

Dynamics

- Peripheral

"development of a set of initial extreme

Validation

- Scenario-level scenarios... representing in simple terms best- and worst-case conditions"

This information is not shared in the report.

"Best scenario: Taking advantage and making the very best of opportunities provided."

"Local Scenario A1: Government set a remit for the regional bodies to bring diverse groups and communities together to focus on common strategic objectives... Let me welcome you to our region where we have built our own future."

"Local Scenario B1: This saw the spawning of localized initiatives addressing a range of social issues. Gradually the economy became one orientated toward addressing needs rather than wants and alternative trading schemes... Let me welcome you to our region where we have safeguarded our future."

"Worst scenario: Failing to capitalize and opportunities offered...Inaction, decline and the culture of despair and learned helplessness."

"Local Scenario A2: Attempts to bring the region together failed as old rivalries, mistaken perceptions and short-term opportunism shaped the agenda... Let me welcome you to our region where we have wasted our future."

"Local Scenario B2: ... set the scene for economic, social and infrastructure deterioration over the decade... Let me welcome you to our region where we have no future."

(pp. 234, 236)

(pp. 234, 236)

(pp. 231, 235)

(p. 237)

"..the scenarios were agreed as possible and plausible." 
Variable mixture

- Interdisciplinary Ten themes emerged from participants

after using PESTEL framework

Variable types

- Hybrid?

Not explicitly discussed.

Deviation

- Alternative

"For each, we then built two alternative

(pp. 235, 236) local narratives."

Table 10.2 presents four Higher-level

Scenarios of 'Best' case and 'Worst'

case.

Quantity

- Four Local Scenario A1, Local Scenario B1,

(pp. 234, 236)

Local Scenario A2, Local Scenario B2

\section{Section 4: Decision makers \\ Scenario - Within impact}

Organisational capacity

- $\quad$ Abandonment

Uncertainty strategy

- $\quad$ Static

- $\quad$ Fixed

Implementation

- Business-asusual
Even though the process was trusted and politically backed, "changes of government and actors that militate against continuity... and against coordinated action towards a better future" and "not actually putting the resources in place to achieve it."

"senior regional stakeholders who had participated in some or all of the earlier [scenario] sessions"

The SP group members speak of external factors beyond their control that will eventually resolve themselves. Internal factors almost beyond their control, such as "cognitive and political lock-in."

"nothing has changed" and "what would be the reason for us to actually do something different when for the last 20 years what we've been doing, we haven't really changed"

Note. The "?" is used when the details necessary to inform the CSI dimension are not explicitly discussed within the text. 


\section{Appendix C}

Table 5. SP profiles of the WE typology themes.

\begin{tabular}{|c|c|c|c|}
\hline \multirow{2}{*}{$\begin{array}{l}\text { CSI typology } \\
\text { dimensions }\end{array}$} & \multicolumn{3}{|c|}{ WE typology themes } \\
\hline & Problem-focused & Actor-centric & RIMA \\
\hline \multicolumn{4}{|l|}{$\begin{array}{l}\text { Section 1: } \\
\text { Project goal }\end{array}$} \\
\hline Epistemology & Cartesian & Non-Cartesian & Non-Cartesian \\
\hline Control & Passive & $\begin{array}{l}\text { Reactive } \\
\text { Preactive } \\
\text { Proactive }\end{array}$ & $\begin{array}{l}\text { Reactive } \\
\text { Reflexive }\end{array}$ \\
\hline Value/reality & Descriptive plausible & Normative passive & $\begin{array}{l}\text { Dynamic with } \\
\text { Descriptive hypothetical } \\
\& \text { Normative active }\end{array}$ \\
\hline Vantage point & $\begin{array}{l}\text { Forward-casting, } \\
\text { inductive }\end{array}$ & All & Bi-directional \\
\hline Motivation & Preserving & Transforming & Transforming \\
\hline Application & Generic & Specific & All \\
\hline Subject & Issue-based & Institution-based & Area-based \\
\hline Variable space & External \& Policy & Internal & Multi-scale \\
\hline Horizon & Single time horizon & Single time horizon & $?$ \\
\hline Geographic scope & All & All & All \\
\hline \multicolumn{4}{|l|}{$\begin{array}{l}\text { Section 2: } \\
\text { Process design }\end{array}$} \\
\hline Practitioners & $\begin{array}{l}\text { (Objective) Experts, } \\
\text { Scientists }\end{array}$ & $\begin{array}{l}\text { Stakeholders \& decision } \\
\text { makers }\end{array}$ & $\begin{array}{l}\text { Stakeholders \& decision } \\
\text { makers }\end{array}$ \\
\hline Groups & Homogeneous & Heterogeneous & Heterogeneous \\
\hline Data & Quantitative & Qualitative & Complimenting \\
\hline Data collection & $\begin{array}{l}\text { Desk research } \\
\text { Dynamic modelling }\end{array}$ & $\begin{array}{l}\text { Participatory (primary) } \\
\text { Desk research }\end{array}$ & Blended \\
\hline Resources & Limited & Complex & Extensive or Complex \\
\hline Institutional conditions & Constrained & $\begin{array}{l}\text { Open or } \\
\text { Structured }\end{array}$ & Open \\
\hline \multicolumn{4}{|l|}{$\begin{array}{l}\text { Section 3: } \\
\text { Scenario content }\end{array}$} \\
\hline Temporal nature & Chain & Varied & Varied \\
\hline Complexity & $?$ & $?$ & High \\
\hline Integration & $?$ & $?$ & High \\
\hline Theme & $?$ & $?$ & $?$ \\
\hline Dynamics & $?$ & $?$ & Compound \\
\hline Validation & Model-level & $\begin{array}{l}* \text { Scenario-level } \\
\text { combination }\end{array}$ & $\begin{array}{l}\text { Combination } \\
\text { (continued on next page) }\end{array}$ \\
\hline
\end{tabular}




\begin{tabular}{|c|c|c|c|}
\hline Variable mixture & $\begin{array}{l}\text { Unknown but favours } \\
\text { intradisciplinary }\end{array}$ & $\begin{array}{l}\text { Unknown but favours } \\
\text { interdisciplinary }\end{array}$ & Interdisciplinary \\
\hline Variable types & $\begin{array}{l}\text { Predetermined (primary) } \\
\text { Uncertainties }\end{array}$ & Hybrid & Hybrid \\
\hline Deviation & $?$ & Alternative & $\begin{array}{l}\text { Conventional \& } \\
\text { Alternative }\end{array}$ \\
\hline $\begin{array}{l}\text { Quantity } \\
\text { 4: } \\
\text { io impact }\end{array}$ & $\geq 2$ scenarios & $\geq 2$ scenarios & $>2$ scenarios \\
\hline Decision makers & Outwith & Within & Within \\
\hline nisational capacity & $?$ & Selective Adoption & Engagement \\
\hline ncertainty strategy & $\begin{array}{l}\text { Static uncertainties are } \\
\text { given either a flexible or } \\
\text { hedging strategy }\end{array}$ & $\begin{array}{l}\text { Dynamic uncertainties } \\
\text { are met with an adaptive } \\
\text { strategy }\end{array}$ & $\begin{array}{l}\text { Quasi-static uncertainties } \\
\text { with signposting. } \\
\text { (primary) }\end{array}$ \\
\hline & & & $\begin{array}{l}\text { Dynamic uncertainty } \\
\text { with adaptive strategies }\end{array}$ \\
\hline Implementation & $?$ & Transformational & $\begin{array}{l}\text { Transformational: mostly } \\
\text { semi-structured }\end{array}$ \\
\hline
\end{tabular}

Section 4:

\section{Scenario impact}

\author{
Organisational capacity \\ Uncertainty strategy
}

Within

Dynamic uncertaintie are met with an adaptive strategy

semi-structured

Note. Some of the CSI dimensions are not discussed in the WE typology themes. For unclear/undiscussed dimensions, "?" is used as a placeholder. For themes that could apply to all the categories within a single characteristic, "All” is entered.

* The scenarios are free from quantitative modelling efforts, therefore validation is a combination of scenariolevel sub-categories, and not the more broad combination of both scenario-level and model-level validation. 